\title{
Evaluation of a bias correction method applied to downscaled precipitation and temperature reanalysis data for the Rhine basin
}

\author{
W. Terink ${ }^{1}$, R. T. W. L. Hurkmans ${ }^{1, *}$, P. J. J. F. Torfs ${ }^{1}$, and R. Uijlenhoet ${ }^{1}$ \\ ${ }^{1}$ Hydrology and Quantitative Water Management Group, Wageningen University, Wageningen, The Netherlands \\ *now at: Bristol Glaciology Centre, School of Geographical Sciences, University of Bristol, Bristol, UK
}

Received: 23 December 2009 - Published in Hydrol. Earth Syst. Sci. Discuss.: 13 January 2010

Revised: 6 April 2010 - Accepted: 8 April 2010 - Published: 22 April 2010

\begin{abstract}
In many climate impact studies hydrological models are forced with meteorological data without an attempt to assess the quality of these data. The objective of this study was to compare downscaled ERA15 (ECMWF-reanalysis data) precipitation and temperature with observed precipitation and temperature and apply a bias correction to these forcing variables. Precipitation is corrected by fitting it to the mean and coefficient of variation $(\mathrm{CV})$ of the observations. Temperature is corrected by fitting it to the mean and standard deviation of the observations. It appears that the uncorrected ERA15 is too warm and too wet for most of the Rhine basin. The bias correction leads to satisfactory results, precipitation and temperature differences decreased significantly, although there are a few years for which the correction of precipitation is less satisfying. Corrections were largest during summer for both precipitation and temperature. For precipitation alone large corrections were applied during September and October as well. Besides the statistics the correction method was intended to correct for, it is also found to improve the correlations for the fraction of wet days and lag-1 autocorrelations between ERA15 and the observations. For the validation period temperature is corrected very well, but for precipitation the RMSE of the daily difference between modeled and observed precipitation has increased for the corrected situation. When taking random years for calibration, and the remaining years for validation, the spread in the mean bias error (MBE) becomes larger for the corrected precipitation during validation, but the overal average MBE has decreased.
\end{abstract}

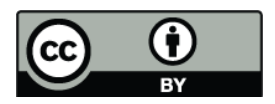

Correspondence to: $\mathrm{W}$. Terink (wilco.terink@wur.nl)

\section{Introduction}

Regional Climate Models (RCMs) are an important source of climate input for hydrological models. RCMs are often employed for downscaling General Circulation Model (GCM) output and reanalysis data. Hydrological models are subsequently forced with RCM data to address the impact of climate change on the hydrological response of river basins. For example de Wit et al. (2007) investigated the impact of climate change by applying the HBV model (Bergström and Forsman, 1973; Lindström et al., 1997) to the Meuse basin, Kleinn et al. (2005) investigated the impact of climate change to the Rhine basin by forcing the WaSiM-ETH model with regional climate model (RCM) output, and Hurkmans et al. (2010) investigated the impact of climate change on streamflow dynamics of the Rhine basin by forcing the Variable Infiltration Capacity (VIC) model (Liang et al., 1994) with different climate scenarios. Another example of the use of RCM output as input for hydrological applications is given by Kay et al. (2006), who used the output of HadRM3H (RCM) as input for a hydrological model to provide estimates of change in flood frequency between the 1970s and 2080s, for 15 catchments across Great Britain. In addition, Steele-Dunne et al. (2008) evaluated the impact of climate change on nine Irish catchments by forcing the HBV-light model with RCA3 (RCM) output to simulate streamflow in a reference period (1961-2000) and a future period (2021-2060) under the Special Report on Emissions Scenarios (SRES) A1B scenario.

Nowadays, modelers are aware of the uncertainty involved in modeling, and the necessity to quantify the model output reliability (Beven, 1989). Spatially distributed models are often forced with RCM output (e.g., REMO, Jacob, 2001), because observations are scarce on the spatial and temporal resolution at which these spatially distributed models are employed. However, in many of these climate impact studies (e.g., Middelkoop et al., 2001), the hydrological model is

Published by Copernicus Publications on behalf of the European Geosciences Union. 
forced with RCM data, without an attempt to assess the quality of the RCM data. Obviously, the reliability of the spatially distributed model output is strongly dependent on the quality of the climate forcing data. Christensen et al. (2008) state that one inherent source of uncertainty comes from the RCM's inability to simulate present-day climate conditions accurately. Therefore it is of major importance that RCM output is validated with historical observations, before calibrating the hydrological model with the RCM data. Applying a bias correction to the RCM data often seems necessary to match the RCM data with the observations (Shabalova et al., 2003; Kleinn et al., 2005; Leander and Buishand, 2007). It is hoped that the model skill under present day conditions is carried over to future climate conditions.

The major objective of this study was to compare observed precipitation and temperature data with downscaled ERA15 data (downscaled with the RCM REMO), refered to as ERA15/REMO hereafter, investigate if there exists a certain bias between the latter two, and finally apply a bias correction to correct for this bias. Our second objective was to test how well the correction parameters determined for a certain calibration period correct for the bias during a validation period.

Several studies have been performed in which a bias correction method was applied to RCM data. For example, Hay et al. (2002) applied a gamma transform to correct RegCM2 precipitation data and Leander and Buishand (2007) applied a power law transform, which corrects for the coefficient of variation $(\mathrm{CV})$ and mean of the precipitation values. Hay et al. (2002) found that the corrected precipitation data did not contain the day-to-day variability which was present in the observed data set. For this reason we have chosen to apply the method developed by Leander and Buishand (2007) in this study, because for hydrological purposes we think it is important that the day-to-day variability of precipitation remains preserved.

This research is part of a larger research project in which the bias-corrected ERA15/REMO precipitation and temperature fields are used to calibrate the VIC model. The calibrated VIC model has been used for a climate impact study for the Rhine basin and is described in more detail by Hurkmans et al. (2010). We hope the results of this bias correction study will facilitate other hydrologists in their search for a suitable bias correction method. The bias correction method employed in this study can easily be applied to other river basins if there is enough forcing and observational data available.

Section 2 describes the area of interest for this study. This study uses data from a meteorological model. The meteorological forcing data and observed data are also subject of Sect. 2. Section 3 explains the methodology used to correct for the bias. The results of the analyses are described in Sect. 4. Finally, Sect. 5 presents the conclusions and perspectives.

\section{Models and data}

The Rhine basin is one of the largest river basins in Western Europe. The river Rhine originates in the canton of Graubünden in the Swiss Alps and it drains portions of Switzerland, Germany, France, Austria and the Netherlands before draining into the North Sea. Approaching the Dutch border, the Rhine has an annual mean discharge of $2395 \mathrm{~m}^{3} \mathrm{~s}^{-1}$ and an average width of $400 \mathrm{~m}$. Because of the various bifurcations in the lower Rhine, only the part upstream of Lobith (the point where the river crosses the German-Dutch border) is considered in this study. The area of the Rhine upstream of Lobith is about $185000 \mathrm{~km}^{2}$ (Hurkmans et al., 2008). Figure 1 represents the Rhine basin upstream of Lobith.

The bias correction is determined for ERA15/REMO reanalysis data for the period 1979-1995. ERA15/REMO data consists of downscaled ERA15 extended with operational reanalysis data to have a total period of 17 years (ECMWF re-analysis $\left.{ }^{1}, 1979-1995\right)$. It contains reanalyses of multidecadal series of past observations, and it has become an important and widely utilized resource for the study of atmospheric and oceanic processes and predictability. It is known that ERA15 has problems with precipitation estimates (Zolina et al., 2004). These problems involve the parameterizations for the convective and stratiform parts, spin-up effects (Kallberg, 2002; Hagemann et al., 2002), and assimilation of different inputs which affect the model solution, including precipitation. Many of these problems are partly accounted for in ERA40, which shows better consistency in many precipitation characteristics (Zolina et al., 2004). ERA40, however, was not downscaled by the REMO model to the resolution needed for our hydrological applications. Therefore we were restricted to use ERA15 in our study. ERA15 was downscaled in two steps at the Max Plack Institute for Meteorology in Hamburg, Germany, to a resolution of $0.088^{\circ}$, using their RCM REMO (Jacob, 2001). In the first step REMO was nested within ERA15 (global) at a resolution of $0.44^{\circ}$. In the second step a REMO domain was nested in the first one. This resulted in a high resolution data set $\left(0.088^{\circ}\right)$ for the Rhine and Elbe basins (Jacob et al., 2008). To run the VIC model, several forcing parameters are necessary (i.e., precipitation, temperature, wind speed, incoming short- and longwave radiation, vapour pressure and specific humidity). The bias correction is determined for precipitation and temperature only, because unfortunately no observations were available for the remaining parameters. Therefore, these parameters are left uncorrected.

Observations of precipitation and temperature were made available by the International Commission for the Hydrology of the Rhine basin (CHR) (Sprokkereef, 2001). They provide daily values of precipitation and temperature for 134 sub-basins (Fig. 1) throughout the Rhine basin for the period

\footnotetext{
${ }^{1}$ http://www.ecmwf.int
} 

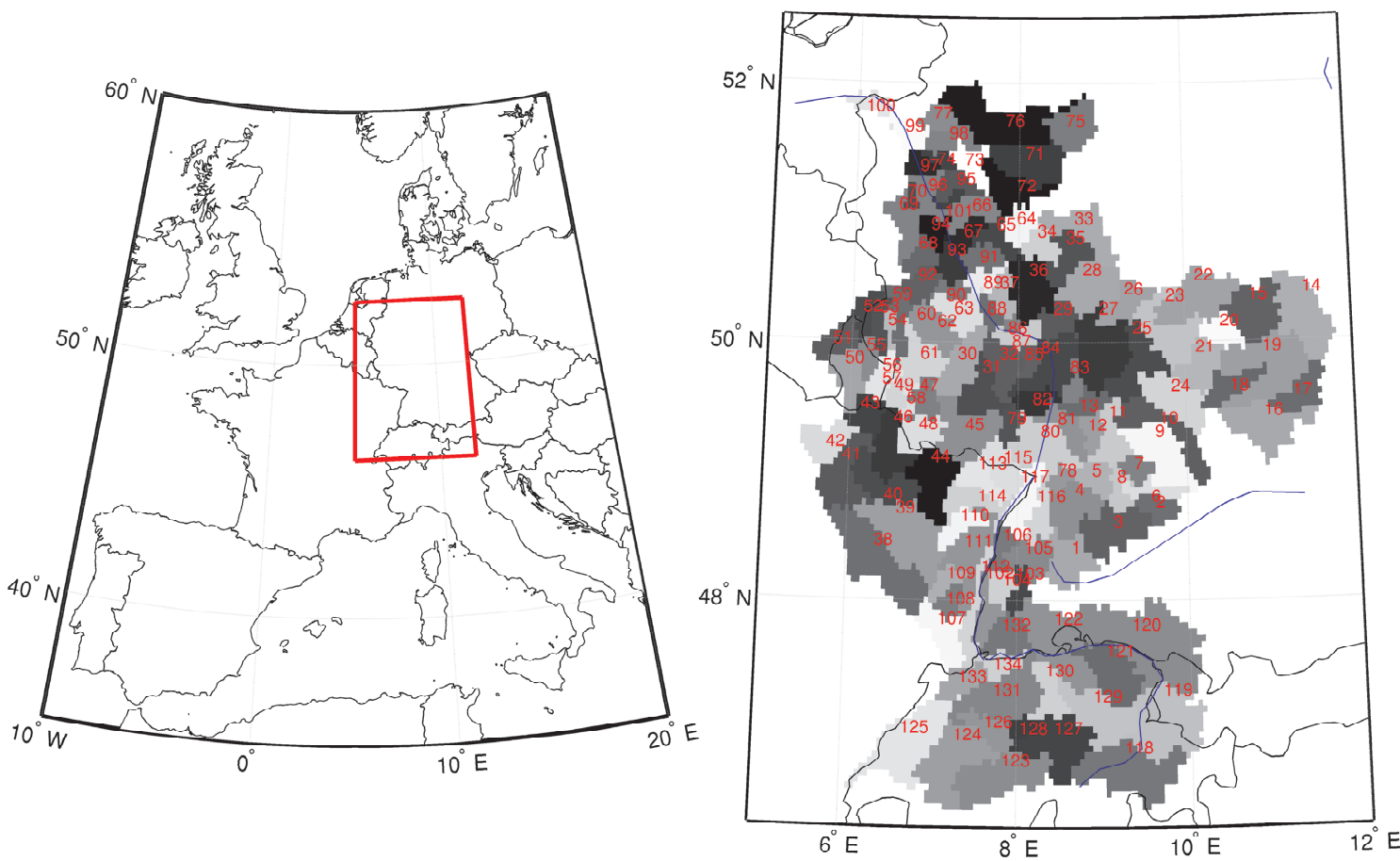

Fig. 1. Left: location of the Rhine basin in Europe. Right: location of the 134 sub-basins for which observations are available at a temporal resolution of 1 day.

1961-1995. The sub-division into 134 sub-basins has been employed for several previous studies in which the HBV model has been applied to the Rhine basin (Eberle et al., 2002, 2005; Mülders et al., 1999). Daily sub-basin values are obtained using meteorological stations in Germany (DWD), Switzerland and France. For the German part of the basin the DWD uses data from ca. 4000 stations. The DWD has interpolated the observations to their REGNIE (Regionaliserung räumlicher Niederschlagsverteilung) grids with a resolution of $60^{\prime \prime}$ longitude and $30^{\prime \prime}$ latitude using the following steps (de Wit and Buishand, 2007; Weerts et al., 2008):

1. The available stations were assigned to the nearest gridpoint of the REGNIE-grid and the relative value to the monthly average rainfall (based on the period 19611995) was calculated. At that grid-point, this relative value was directly used;

2. For all other grid-points, the relative values of all stations in a box of 20 grids around that grid-point were used. These relative values were divided by the square of the distance to the central grid-point (i.e. weighted with the inverse square of the distance). The number of employed stations varies with the density of the stations in that region. The average is about three to four;

3. The sub-basin averages are then calculated as arithmetic averages of the grid cell values.
The idea behind this approach is that corrections for orography as well as the orientation of the terrain are taken into account through the background grid. For Switzerland (Dällenbach, 2000) and France (White, 2001) a similar procedure was followed, but they used the inverse distance interpolation technique instead of the inverse squared distance interpolation technique. In addition, Brandsma and Buishand (1999) also used these observations provided by the CHR in the first report on multi-site generation of daily precipitation and temperature. Combining the period 1979-1995 of ERA15/REMO with the period 1961-1995 of the observations results in the overlapping period 1979-1995 (17 years) for assessing the bias.

\section{Methodology}

\subsection{Introduction}

The first part of the analysis is based on the determination of the correction parameters for the entire period, while the focus of the second part is on a separate calibration and validation period. With the bias correction we try to match the most important statistics (temporal coefficient of variation (CV), mean and standard deviation) of the ERA15/REMO data with those of the CHR observations. The bias correction applied in this study is based on that proposed by Leander and Buishand (2007) for a Meuse basin study. They 
found that a relatively simple non-linear correction, adjusting both the biases in the mean and variability, leads to a better reproduction of observed extreme daily and multi-day precipitation amounts than the commonly used linear scaling correction. This method of bias correction does not correct for the fraction of wet and dry days and lag-1 autocorrelation. As was mentioned in Sect. 2, we only have observations available per sub-basin at a temporal resolution of one day. We intend to use the bias-corrected data for calibration of the VIC model (Hurkmans et al., 2010). However, we would like to run VIC at a spatial resolution of 0.05 degrees and a temporal resolution of $3 \mathrm{~h}$. For this reason we cannot simply use the observations for calibrating the VIC model, because then all grid cells within a sub-basin would have the same values for precipitation and temperature, implying that there is no spatial variation in the precipitation and temperature fields within a sub-basin. Therefore, the correction parameters for precipitation are determined for each sub-basin to ensure that the temporal CV and mean for ERA15/REMO match those of the observations for that specific sub-basin. Thus, when averaging all the grid cell values within that sub-basin, and applying the correction parameters to the average of these grid cell values, the temporal $\mathrm{CV}$ and mean should match those of the observations. Therefore we first calculate the average daily precipitation for each sub-basin $k$ as:

$\bar{P}_{k, d}=\frac{1}{N} \sum_{i=1}^{N} \sum_{h=1}^{8} P_{k, d, i, h}$

where $\bar{P}$ is the average precipitation for sub-basin $k$ on day $d, P$ the precipitation for cell $i$ and 3-hourly time step $h$, and $N$ the total number of grid-cells within sub-basin $k$. With $\bar{P}_{k, d}$ and the observed daily precipitation values for each sub-basin we are able to determine the correction parameters $a$ and $b$ (for details, see Sect. 3.2). With $a$ and $b$ we subsequently calculate the corrected daily sub-basin precipitation value $\bar{P}_{k, d}^{*}$. Thus we now have a corrected and uncorrected daily precipitation value for each sub-basin. The ratio between the corrected and uncorrected precipitation value is defined as:

$R_{k, d}=\frac{\bar{P}_{k, d}^{*}}{\bar{P}_{k, d}}$

where $R_{k, d}$ is the correction factor to be applied to the each of the uncorrected precipitation cells $i$ within sub-basin $k$, and 3-hourly time steps $h$ during day $d$, according to:

$P_{k, d, i, h}^{*}=P_{k, d, i, h} \cdot R_{k, d}$

The derived correction parameters $a$ and $b$ cannot directly be applied to the 3-hourly grid cell values because the correction function (see Sect. 3.2) is a power law function. If this is done, then the temporal $\mathrm{CV}$ and mean of the spatial average of grid cell values in the sub-basin would not match the $\mathrm{CV}$ and mean of the observations. The bias correction of temperature was found to be more straightforward than that of precipitation, involving shifting and scaling to adjust the mean and variance, respectively. In the following sub-sections, the method used to calculate the bias correction for precipitation and temperature will be described in detail.

\subsection{Precipitation}

Because the bias in precipitation and temperature was found to vary spatially, bias corrections were carried out for each of the 134 sub-basins individually. Leander and Buishand (2007) used a power transformation, which corrects the CV as well as the mean. In this nonlinear correction each daily precipitation amount $P$ is transformed to a corrected $P^{*}$ using:

$P^{*}=a P^{b}$

The sampling variability of the 17 -year means may introduce a systematic effect in the precipitation related results. In this study we employed a length of 65 days to calculate the statistics for. This length is chosen for several reasons:

1. Leander and Buishand (2007) selected 65 days to reduce the sampling variability based on a study by Shabalova et al. (2003), in which HadRM2 precipitation was corrected for a hydrological application to the Rhine basin. Shabalova et al. (2003) state that the sampling variability is reduced using a 70-day window;

2. The block length cannot be chosen to be too small, because then one would be correcting for differences which are caused by natural variability instead of correcting for systematic model errors;

3. A sensitivity analysis for block lengths of $25,35,45$, 65,85 and 105 days revealed that block lengths of 25 , 35 and 45 days improved corrections during September/October, but lead to worse results for July/August. Block lengths of 85 and 105 days resulted in worse performance for nearly all months (Fig. 2);

4. RMSE for daily precipitation differences were smaller for 65-day block lengths than for lengths of 25, 35 and 45 days (Fig. 2);

Thus, in this study we determined the parameters $a$ and $b$ for every five-day period of the year, including data from all years available, in a window including 30 days before and after the considered five-day period. The determination of the $b$ parameter is done iteratively. It was determined such that the $\mathrm{CV}$ of the corrected daily precipitation matches the $\mathrm{CV}$ of the observed daily precipitation. In this way, the CV is only a function of parameter $b$ according to:

$\mathrm{CV}(P)=f(b)$ 

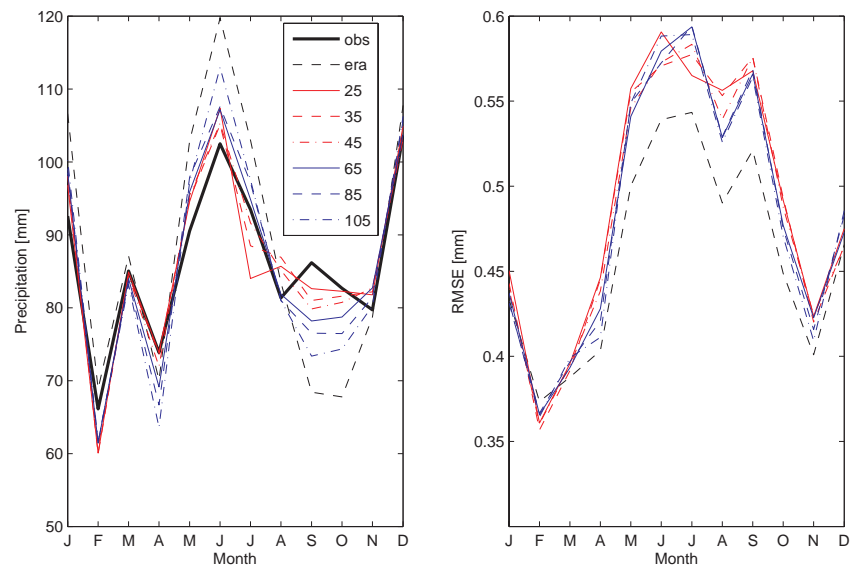

Fig. 2. Left: Average monthly precipitation sums for various block lengths. "obs" denotes the observed precipitation, while "era" denotes the uncorrected ERA15/REMO precipitation. The sensitivities are shown for block lengths of 25, 35, 45, 65, 85 and 105 days. Right: RMSEs of daily precipitation differences for various block lengths.

in which $P$ is the precipitation in a block of 65 days times 17 years. With the determined parameter $b$, the transformed daily precipitation values are calculated using:

$P^{*}=P^{b}$

The parameter $a$ is then determined such that the mean of the transformed daily values corresponds with the observed mean. The resulting parameter $a$ depends on $b$. At the end, each block of 5 days has its own $a$ and $b$ parameter, which are assumed to be the same for each year. The bias correction for the ERA15/REMO data set needs to be calculated for the period 1979-1995, which has a total length of 17 years. Figure 3 illustrates the division of a year into 73 blocks of 5 days. For every 5-day block, a different set of $a$ and $b$ parameters is determined using the method described above. The top panel of Fig. 3 represents the daily precipitation throughout the year. The bottom panel zooms in to the first 65 days of the year resulting in 13 blocks of 5 days each. Parameters of block 7 are calculated using 30 days before and 30 days after the considered block, and taking into account all years for which the bias correction is applied. This results in 1105 $(=17 \times 65)$ values for the calculation of the $\mathrm{CV}$ and the mean.

\subsection{Temperature}

Temperature cannot be corrected using a similar power law as was used for correcting precipitation, because temperature is known to be approximately normally distributed. Correcting a normally distributed data set with a power law function results in a data set which is not normally distributed. Therefore we used a different technique for correcting temperature. The correction of temperature only involves shifting and scaling to adjust the mean and variance (Leander and
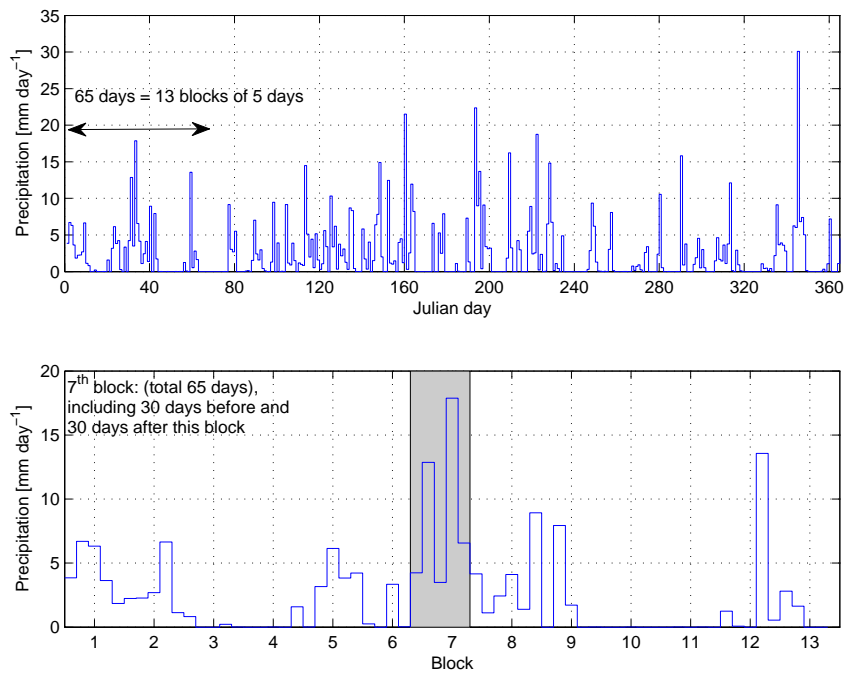

Fig. 3. Schematisation of the division of a year into 73 blocks of 5 days each for which the $a$ and $b$ parameters are determined. Top: daily precipitation throughout the year; Bottom: first 65 days of the year resulting in 13 blocks of 5 days each.

Buishand, 2007). For each sub-basin, the corrected daily temperature $T^{*}$ was obtained as:

$T^{*}=\bar{T}_{\text {obs }}+\frac{\sigma\left(T_{\text {obs }}\right)}{\sigma\left(T_{\text {era }}\right)}\left(T_{\text {era }}-\bar{T}_{\text {obs }}\right)+\left(\bar{T}_{\text {obs }}-\bar{T}_{\text {era }}\right)$

where $T_{\text {era }}$ is the uncorrected daily temperature from ERA15/REMO and $T_{\mathrm{obs}}$ is the observed daily temperature from the CHR data set. In this equation an overbar denotes the average over the considered period and $\sigma$ the standard deviation. This method was not appropriate for precipitation because it may cause negative values. Again both statistics were determined for each 5-day block of the year separately, using the same 65-day windows as for the bias correction of daily precipitation.

\section{Results}

\subsection{Introduction}

In the following sub-sections the data are analyzed spatially and temporally. We analyse how well the relevant statistics (CV, standard deviation and mean) of the corrected ERA15/REMO data match those of the observations after the bias correction has been applied. Extended analyses are done on the behaviour of extremes, fraction of wet days and lag-1 autocorrelations. This is done for precipitation and temperature separately. The sensitivity of the determined $a$ and $b$ parameters is investigated by using bootstrapping (Efron and Tibshirani, 1994). The last sub-section focuses on how well the determined parameters for a calibration period (10 years) correct for the bias in a validation period (7 years). 

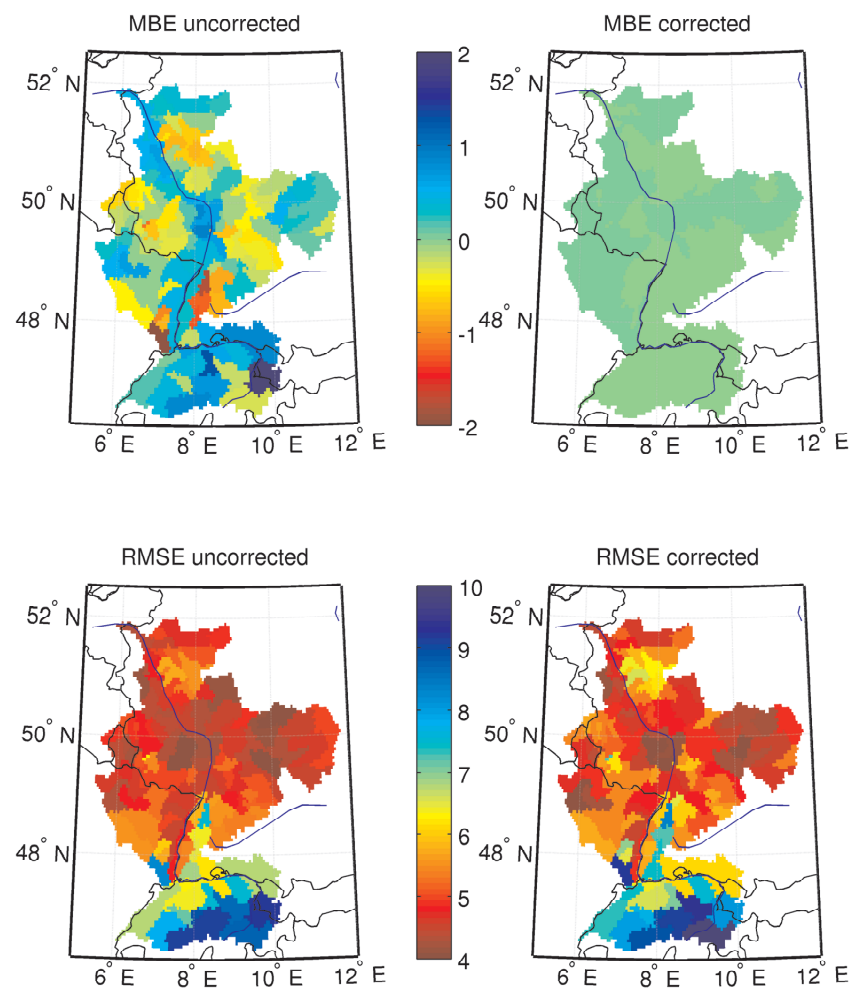

Fig. 4. Top: MBE for the uncorrected and corrected ERA15/REMO precipitation [mm] per sub-basin for the period 1979-1995; Bottom: RMSE for the uncorrected and corrected ERA15/REMO precipitation [mm] per sub-basin for the period 1979-1995.

\subsection{Precipitation}

\subsubsection{Spatial precipitation difference}

The average precipitation is corrected to match the average precipitation for each window of 65 days times 17 years. It would also be of interest to know if the daily average precipitation over the entire period has improved. Therefore the average daily precipitation over the period 1979-1995 has been calculated for each sub-basin separately. The average daily precipitation difference between the observations and ERA15/REMO is given by:

$\mathrm{MBE}=\frac{1}{N} \sum_{i=1}^{N}\left(P_{\mathrm{era}, i}-P_{\mathrm{obs}, i}\right)$

where MBE is the Mean Bias Error, $N$ the number of days, $P_{\text {era }, i}$ the precipitation for ERA15/REMO at day $i$ and $P_{\mathrm{obs}, i}$ the precipitation for the observations at day $i$. The MBE for the uncorrected and corrected situation is shown in the top panel of Fig. 4 for each sub-basin separately. A positive difference means that ERA15/REMO is wetter than the observed precipitation value for that specific sub-basin. As can be seen, the difference between the uncorrected ERA15/REMO and the observations varies between -2 and
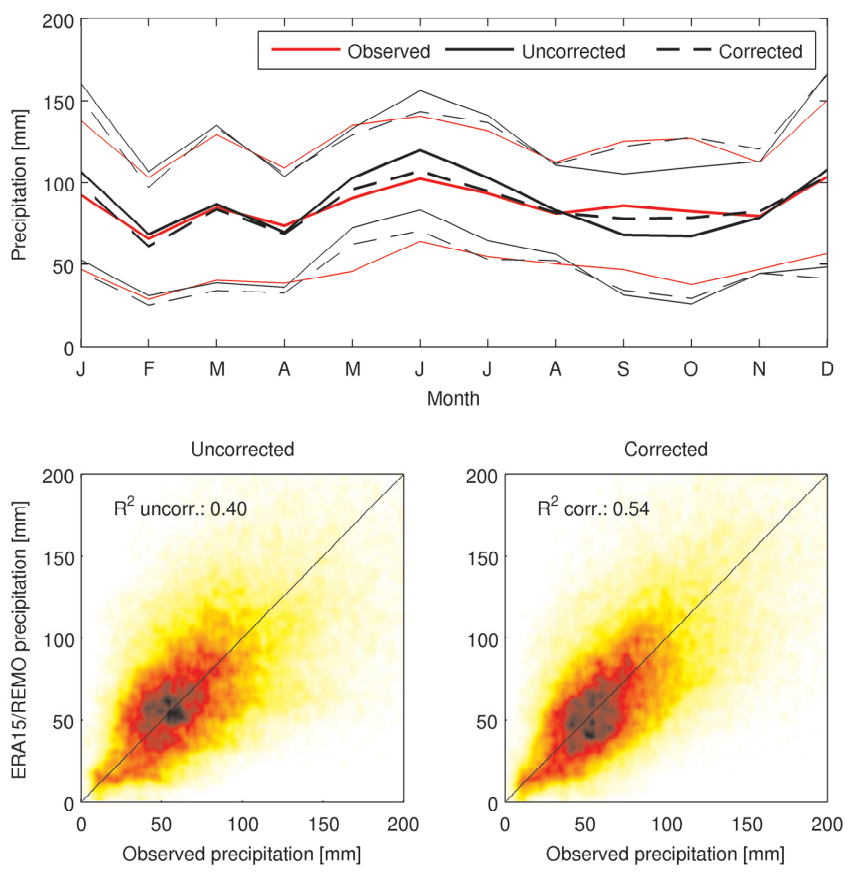

Fig. 5. Top: average monthly precipitation sums [mm] for the observations and the uncorrected and corrected ERA15/REMO data (solid lines). Average monthly precipitation sums +/- one standard deviation are shown as well (thin lines); Bottom: scatter densities for the uncorrected and corrected ERA15/REMO and observed monthly precipitation sums for each year per sub-basin. $R^{2}$ coefficients for the uncorrected and corrected situation are shown as well.

$+2 \mathrm{~mm} \mathrm{~d}^{-1}$. The uncorrected ERA15/REMO precipitation is too wet for most of the Rhine basin, especially in the Alps and in areas close to where the river Rhine is located. From the top right panel of Fig. 4, it can be concluded that the bias correction leads to satisfactory results. Differences between the corrected ERA15/REMO and the observations have decreased notably. The spatial variation in the spread of daily precipitation differences per sub-basin is quantified by the root-mean-square-error (RMSE) of the daily precipitation difference between ERA15/REMO and the observations (bottom panel, Fig. 4) and is given by:

$\mathrm{RMSE}=\sqrt{\frac{1}{N} \sum_{i=1}^{N}\left(P_{\mathrm{era}, i}-P_{\mathrm{obs}, i}\right)^{2}}$

There is hardly any difference in the RMSE of the uncorrected and corrected situation for most of the Rhine basin. The RMSE appears to have increased in some sub-basins and decreased in others. Based on these results it looks like the correction method is less capable of correcting the daily precipitation amount for these particular sub-basins. 


\subsubsection{Temporal precipitation difference}

The Rhine basin is subject to a strong seasonal pattern in which wet winters and dry summers are quite common. This aspect is important for the correct timing of flood peaks. Therefore, we are interested to evaluate how well the biascorrected ERA15/REMO precipitation performs temporally. We already noticed that the daily average over the entire period has improved considerably (top panel Fig. 4). However, it is certainly possible that the average monthly precipitation sums of the corrected ERA15/REMO data differ from those of the observations, although the average ERA15/REMO precipitation over the entire period is unbiased. Average monthly precipitation sums for the observations and the uncorrected and corrected ERA15/REMO data are shown in the top plot of Fig. 5. Averages are calculated as weighted (based on sub-basin size) averages over the period 19791995. Large differences between the observations and the uncorrected ERA15/REMO can be seen during May, June, July, September and October. However, the bias correction seems to correct for this bias reasonably well. It seems that the correction method is less capable of correcting the monthly precipitation sums during February, April and November. However, the method was developed to correct for the mean and $\mathrm{CV}$ for blocks of 65 days, in which the determined 5-day $a$ and $b$ parameters will have an effect on the statistics of the neighbouring and partly overlapping 65 -day blocks. Therefore, it may happen that average monthly precipitation sums of the uncorrected ERA15/REMO data match those of the observations better than the corrected ERA15/REMO data does.

It can be noticed that precipitation is corrected from a wet to a drier situation for almost the entire year. Considering Fig. 5, the wet bias is especially large during summer. According to Frei et al. (2003), who studied precipitation statistics for the European Alps, wind field deformation and deflection of hydrometeors over the gauge orifice results in a systematic measurement bias. Estimates of this error for the Alpine region are largest in winter (high wind speed, high fraction of snowfall), when the undercatch is about $8 \%$ for gauges below $600 \mathrm{~m}$ above sea level. For summer the undercatch varies between $4 \%$ at low and $12 \%$ at high-altitude stations. Therefore the large wet bias during summer could partly be a result of a systematic undercatch in the rain gauges. However, the undercatch is relatively small (only 4\%) for the largest part of the Rhine basin during summer. Instead of individual rain gauges, we used sub-basin averaged precipitation values, which are calculated using advanced interpolation techniques in which orography and orientation of the terrain are taken into account (see Sect. 2). Based on this we assume that the effect of overcorrecting for undercatch is minimal.

In September and October the correction is the other way around, and according to the top plot of Fig. 5 the described method has some difficulties in correcting for this shift. This suggests that the employed method is less capable of correcting the precipitation sum if the observed precipitation and ERA15/REMO precipitation show an opposite signal. This minimum for ERA15/REMO precipitation in September and October was also found by Kotlarski et al. (2005). They compared 3 reference data sets with downscaled ERA15, using 4 different RCMs. Kotlarski et al. (2005) found an overestimation of precipitation in REMO in June and subsequently a strong decrease of mean monthly rainfall until September. This is probably connected to the annual cycle of vegetation characteristics implemented in this model, which causes strong evaporation in early summer and consequently a rapid decline of soil water storage. In late summer, the dry soil prevents evaporation and therefore local water supply for the atmosphere, resulting in a decrease of precipitation. This latesummer drying problem was also found by Hagemann and Jacob (2007), who used an ensemble of 10 RCMs to conduct climate simulations for current and future climate conditions. A late-summer drying problem was found for all RCMs over Central Europe and is a common feature in several RCMs.

The correction method applied in this study uses the same $a$ and $b$ parameters for each year. We noticed that the correction method performs quite well when considering the average monthly precipitation sums. It remains to be seen how well the method performs when considering individual years. To answer this question, the average monthly precipitation sum plus and minus one standard deviation has been plotted as well (thin lines). Considering these results it seems that the correction method works quite well for the months May until October, but for November until April there are three years in which the uncorrected data matches the observations better than the corrected data does. To consider both the monthly performance for each year and the performance per sub-basin, the bottom plots of Fig. 5 represent the relation between the observed and ERA15/REMO monthly precipitation sums for each year per sub-basin, both for the uncorrected (left plot) and corrected (right plot) situation in a scatter density plot. It can be noticed that the monthly precipitation sums for the corrected situation match those of the observations better than those of the uncorrected situation. Based on these results we conclude that the overall performance of the ERA15/REMO precipitation has improved, although there are a few years for which the uncorrected ERA15/REMO precipitation performs better.

\subsubsection{Variation and sensitivity of parameters}

The determined $a$ and $b$ parameters affect the corrected daily precipitation value. It is of major importance how sensitive these parameters are to the period for which they were determined. What would happen with the parameters if we had selected a different time period for determing the parameters? The two left panels of Fig. 6 show boxplots for the $a$ and $b$ parameters throughout the year. These boxplots are calculated for each block of 5 days, taking into account the 

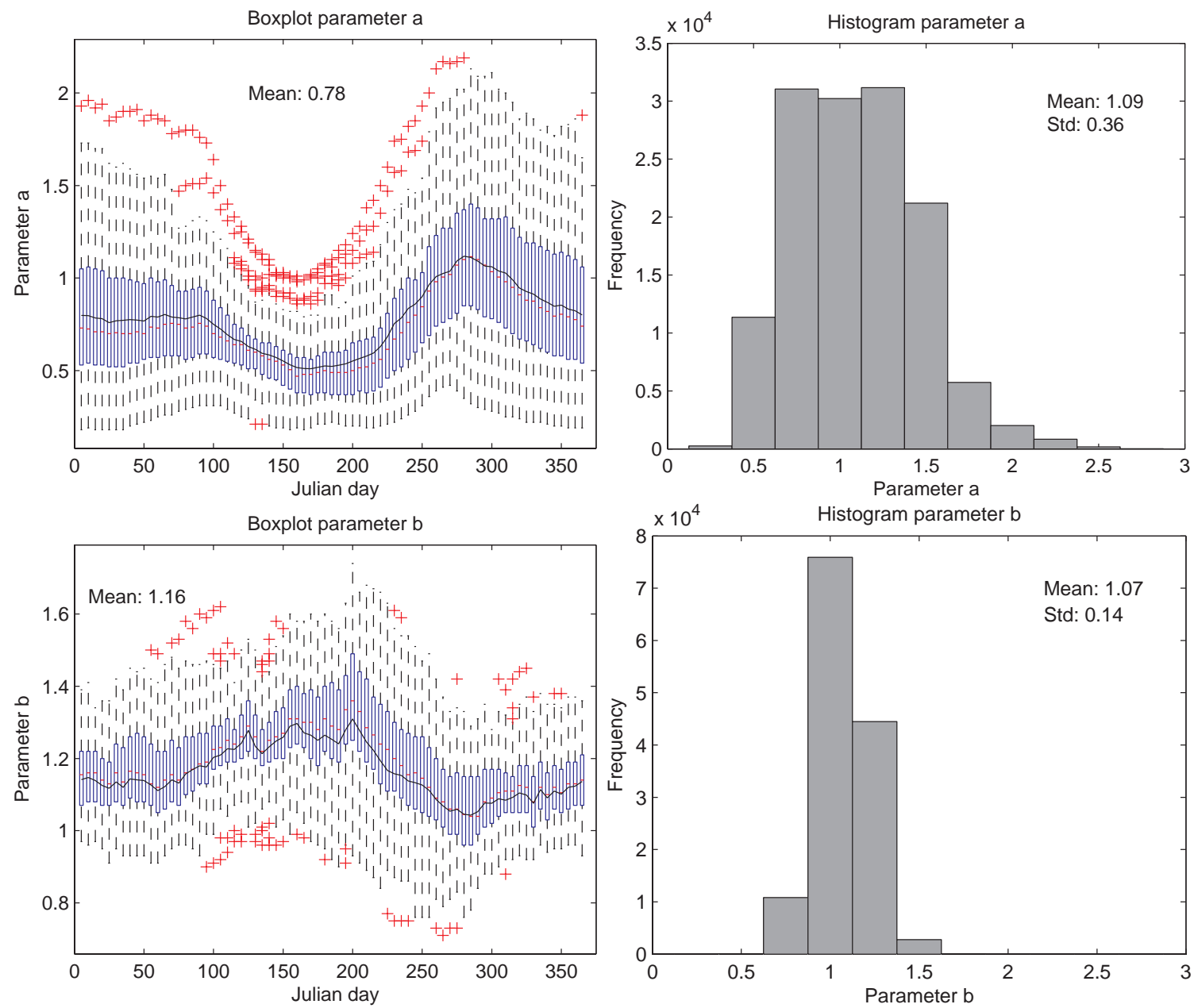

Fig. 6. Top left: boxplot for parameter $a$ for each block of 5 days. The boxplot is calculated taking into account the values from all subbasins. Median values are represented with the horizontal red lines. Area-weighted average parameter values are shown with the black solid line. Outliers (red crosses) are calculated as values larger than 1.5 times the interquartile range. Top right: histogram of bootstrap values for parameter $a$ for 1000 random samples of 65 days from 17 years of data. Samples are taken from each of the sub-basins and from block 55, including 30 days before and after this block. Bottom left: boxplot for parameter $b$. Bottom right: histogram of bootstrap values for parameter $b$ for block 55 .

values from all sub-basins. Outliers are defined as values larger than 1.5 times the interquartile range and are indicated with red crosses. It is clear that parameter $a$ is smaller than one during almost the entire year. Parameter $a$ was determined to fit the mean of ERA15/REMO with that of the observations. It can be concluded that the average precipitation has to be corrected from a wet to a drier situation for almost the entire year. This correction is especially large during summer, as was already noticed from Fig. 5. However, the spread in the $a$-parameter is smallest during summer. This spread is large during winter, which implies a large variation in the $a$-parameter for the various sub-basins. It could be that the uncertainty of the $a$-parameter is large during winter. Outliers indicate sub-basins, especially during the first 280 days of the year, for which the $a$-parameter is substantially larger or smaller than for most of the sub-basins. Sub-basin 1 (see Fig. 1) is an outlier during almost the entire year. Subbasin 119 (eastern part of Switzerland) has an $a$-parameter which is smaller than 1.5 times its interquartile range for the 26th and 27th block. The spread in the $b$-parameter (Fig. 6 bottom left panel) is smaller than was the case for parameter $a$. Outliers can be found throughout the entire year, except for the first 55 days of the year. Large outliers for $b$ occur mainly in sub-basin 107. Small outliers for $b$ occur mainly for sub-basin 1. Parameter $b$ is larger than one during almost the entire year. The CV has to be corrected most during the summer months.

To address the uncertainty concerning the determined $a$ and $b$ parameters, we applied bootstrapping for block 55 and all sub-basins. This is done because for this block the 
spread in both $a$ and $b$ is quite large. We took 1000 random samples of 65 days from the 17 years of data available for block 55, and determined for each sample a new $a$ and $b$ parameter. The bootstrapping procedure is performed for each of the sub-basins individually. The results of this analysis are shown in the two histograms of Fig. 6. It can be concluded that the uncertainty range for parameter $a$ is larger than for parameter $b$. In other words, the largest uncertainty is associated with correcting the mean of the precipitation values.

\subsubsection{Statistics}

In Sect. 3 we described the method of the bias correction, that is employed to fit the mean and CV for the precipitation data. Figure 7 shows several scatter plots for the fitting statistics as well as for the fraction of wet days ( $\left.f_{\text {wet }}\right)$ and the lag1 autocorrelations. These statistics are calculated for each of the sub-basins separately, resulting in 134 data points for each graph. The observed statistics are plotted versus those of the uncorrected and corrected ERA15/REMO data.

Of course the mean, standard deviation and CV of the observations match those of the corrected ERA15/REMO almost perfectly, because those were the fitting criteria. Interestingly, also the correlation between the fraction of wet days in the observations and in ERA15/REMO has improved significantly for the corrected ERA15/REMO data. Also the lag-1 autocorrelations of the corrected ERA15/REMO data match those of the observations better than those of the uncorrected ERA15/REMO data. These results can be considered as good, because the method of bias correction applied in this study was only intended to correct for the CV and mean, not for the fraction of wet days or the lag-1 autocorrelation.

For climate impact studies it is important that the hydrological model is capable of simulating the runoff generated by large multi-day precipitation events well enough. These large multi-day precipitation events often result in floods. Therefore, we have selected all 10-day precipitation sums during winter. The non-exceedance probabilities for these 10-day precipitation sums have been investigated in Fig. 8. According to Furrer and Katz (2008) a Generalized Pareto distribution is capable of fitting high intensity precipitation data. Therefore we have fitted a Generalized Pareto distribution through the data. The Generalized Pareto distribution function is given by:

$y=f(x \mid k, \sigma, \theta)=\frac{1}{\sigma}\left(1+k \frac{x-\theta}{\sigma}\right)^{-1-\frac{1}{k}}$

where $k$ is the shape parameter, $\sigma$ is the scale parameter and $\theta$ is the threshold parameter. Only the fit to the observed 10-day precipitation sums is shown, because the other two fits are similar. All parameters are estimated using the maximum likelihood method (Aldrich, 1997). Both the uncorrected and corrected ERA15/REMO data match the observations well for non-exceedance probabilities smaller than
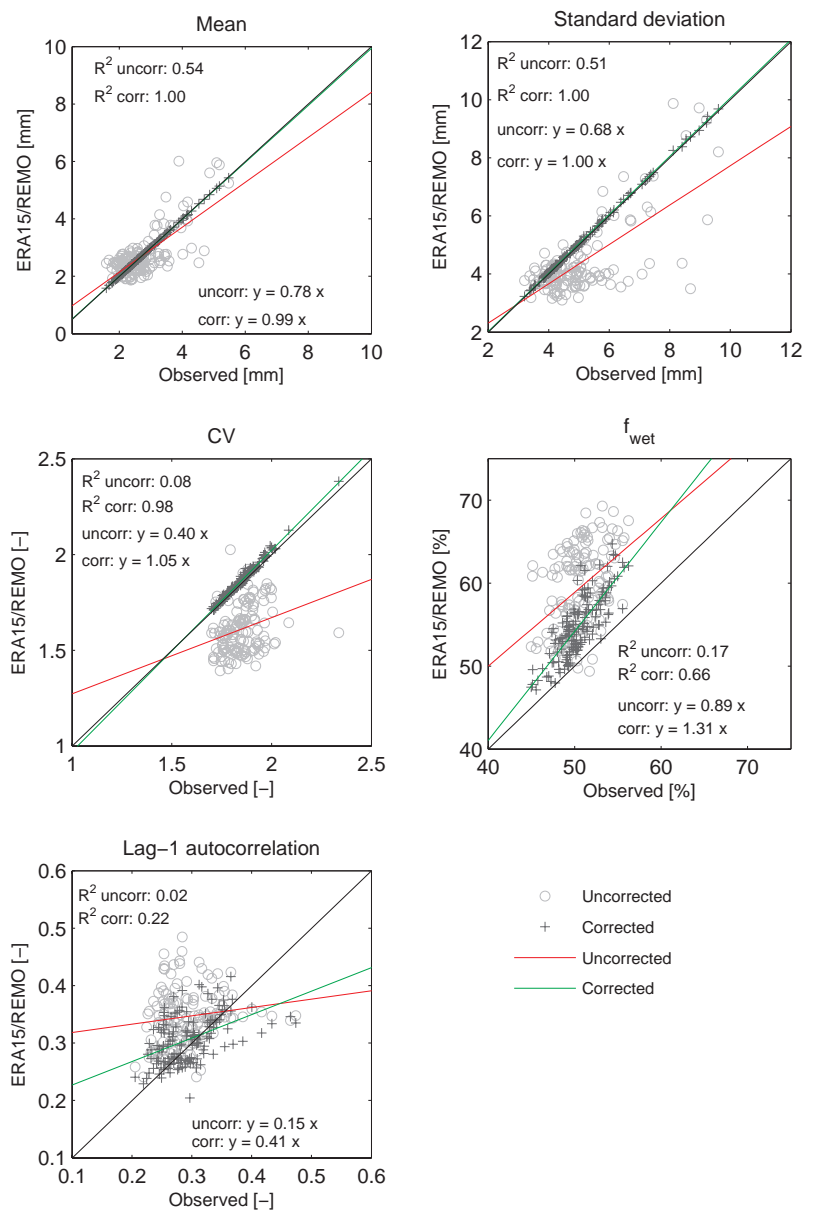

Fig. 7. Scatter plots of the statistics of the observed precipitation versus the corrected and uncorrected ERA15/REMO precipitation. The statistics are calculated for each sub-basin over the period 1979-1995. The fraction of wet days $\left(f_{\text {wet }}\right)$ is the percentage of days where $P>0.3 \mathrm{~mm}$. In each subplot the square of the correlation coefficient $\left(R^{2}\right)$ and slope of the linear regression line are plotted. The black line represents the $x=y$ line.

0.95. However, for non-exceedance probabilities larger than 0.95 the uncorrected ERA15/REMO matches the 10-day precipitation sums of the observations better than the corrected ERA15/REMO does. These differences are, however, quite small. More important is that the distribution of the 10-day precipitation sums is not substantially disturbed by applying a bias correction.

\subsection{Temperature}

\subsubsection{Spatial temperature difference}

The MBE for the uncorrected and corrected ERA15/REMO temperature for each sub-basin is shown in the top left panel of Fig. 9. A positive value corresponds to a higher temperature for the uncorrected ERA15/REMO data set. Differences 


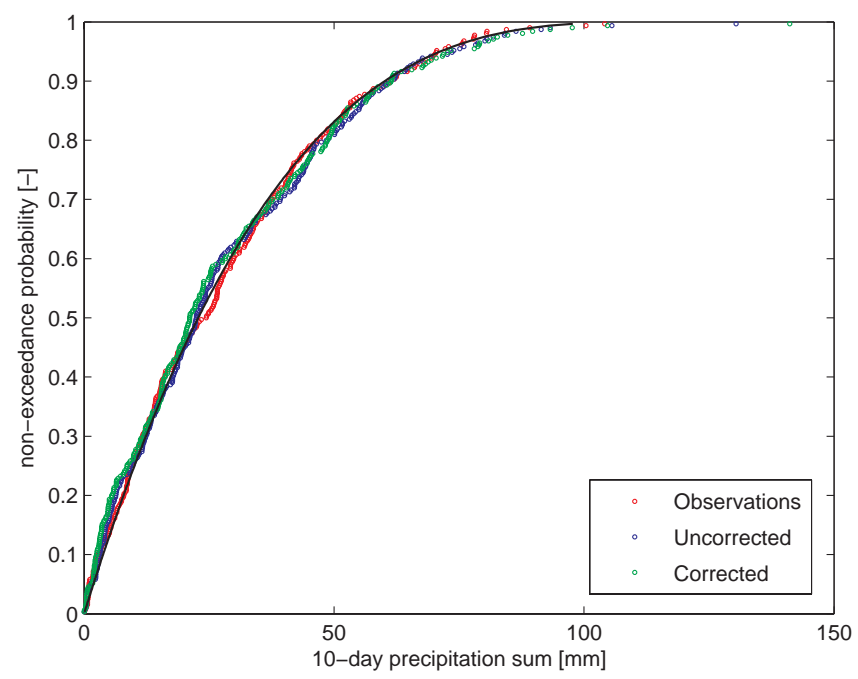

Fig. 8. Non-exceedance probabilities of 10-day winter precipitation sums for the period 1979-1995. The 10-day precipitation sums are area-weighted averages.
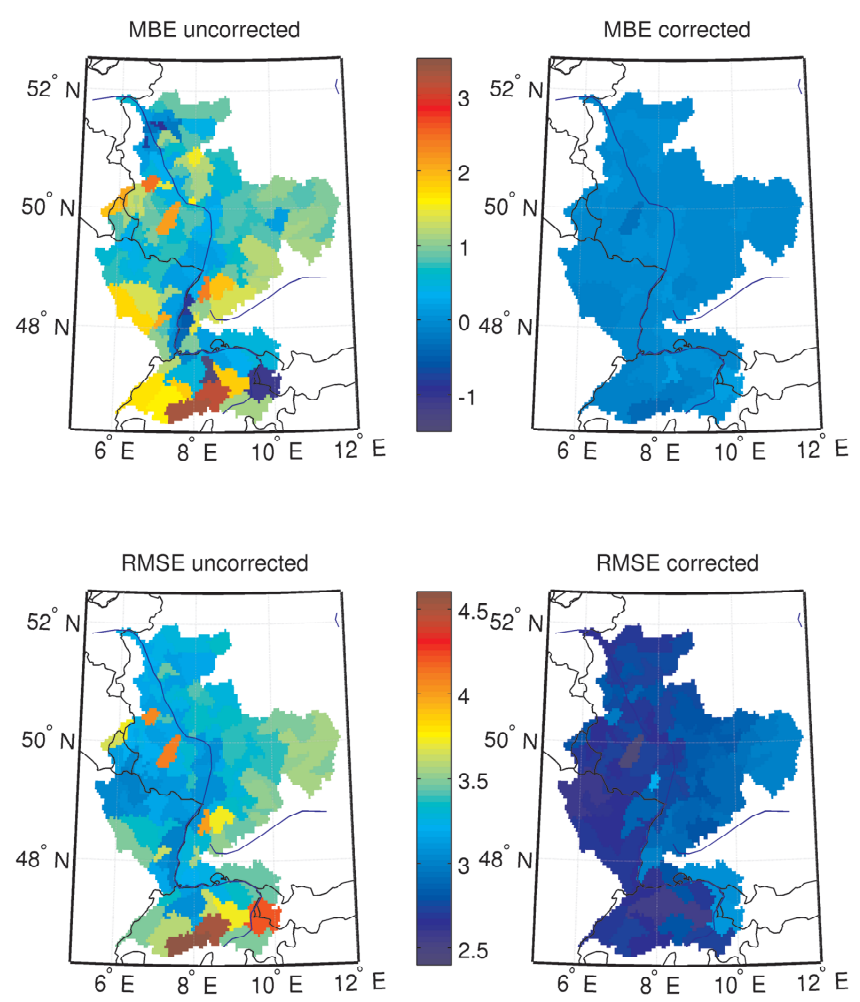

Fig. 9. Top: MBE for the uncorrected and corrected ERA15/REMO temperature $\left[{ }^{\circ} \mathrm{C}\right]$ per sub-basin for the period 1979-1995. Bottom: RMSE for the uncorrected and corrected ERA15/REMO temperature $\left[{ }^{\circ} \mathrm{C}\right]$ per sub-basin for the period $1979-1995$.

in MBE vary between -1.5 and $+3.5^{\circ} \mathrm{C}$ for the uncorrected ERA15/REMO data. The MBE is positive for the largest part of the Rhine basin, which means that the uncorrected

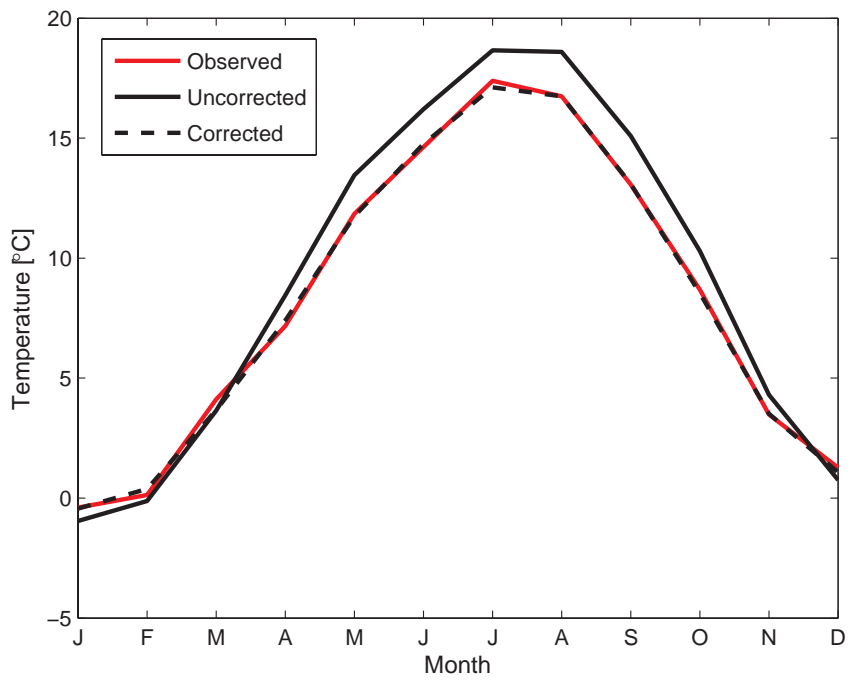

Fig. 10. Area-weighted monthly temperature $\left[{ }^{\circ} \mathrm{C}\right]$ over the entire Rhine basin for the period 1979-1995. Results are shown for the observations and the uncorrected and corrected ERA15/REMO.

ERA15/REMO is warmer than the observations for that part of the Rhine basin. The top right panel of Fig. 9 shows the differences between both data sets after the correction has been applied. It can be concluded that the bias correction for temperature leads to good results. Differences have decreased substantially to values between -0.4 and $+0.4^{\circ} \mathrm{C}$. Another point of interest is the spatial variation in the spread of daily temperature differences per sub-basin. This is quantified by the RMSE of the daily temperature difference between ERA15/REMO and the observations (Fig. 9, bottom panel). In the uncorrected situation the RMSE is quite large for some sub-basins. However, the RMSE for the corrected temperature has decreased significantly. Based on these results it can be concluded that the applied correction method adjusts the daily temperature values very well.

\subsubsection{Temporal temperature difference}

Average monthly temperatures for the period 1979-1995 are shown in Fig. 10. Averages are calculated as area-weighted averages over the entire Rhine basin. With the bias correction we hope to capture the seasonal pattern of temperature. It can be concluded that the bias correction for temperature leads to satisfactory results. The bias-corrected ERA15/REMO temperature matches the observed temperature almost perfectly for each month. Corrections are largest during the summer months and smallest during winter. This is mainly caused by the difference in mean temperature as shown later in Fig. 11.

\subsubsection{Standard deviation and mean}

As mentioned in Sect. 3, the correction of temperature is more straightforward than for precipitation. It only involves correcting for the mean and the standard deviation. Therefore 

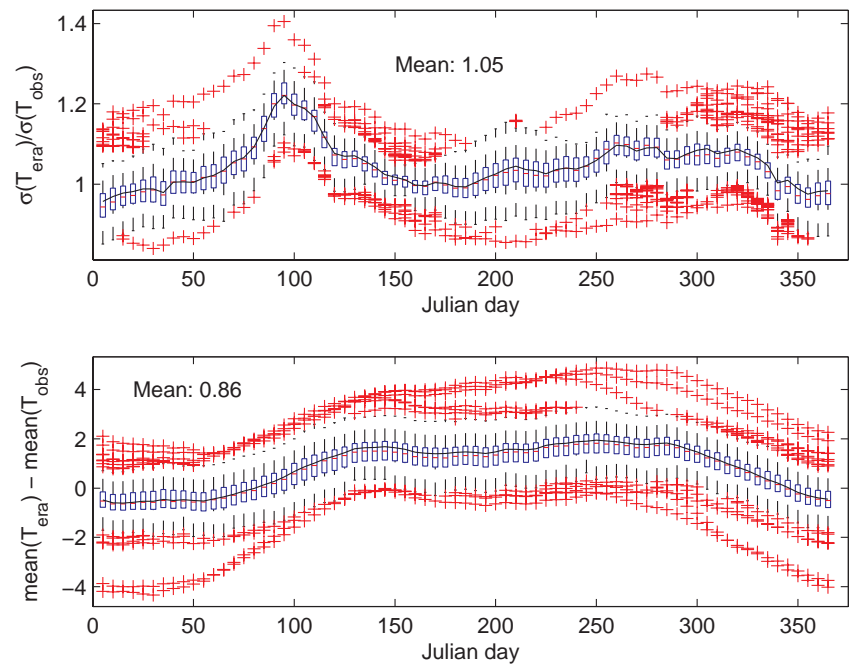

Fig. 11. Top: boxplot for the ratios of the ERA15/REMO standard deviations over the observed standard deviations. Bottom: boxplot for the differences between the ERA15/REMO average temperatures and observed average temperatures. Boxplots are shown for each block of 5 days, where each box represents the spread between all sub-basins. Area-weighted averages for each block of 5 days are represented with the solid black line. Median values are represented with the horizontal red lines while outliers are indicated with the red crosses and are calculated as values larger than 1.5 times the interquartile range.

it is interesting to know how the ratio of the ERA15/REMO standard deviation over the observed standard deviation for temperature varies during the year. The spread in ratios for all sub-basins, before the correction is applied, is represented in the boxplot of Fig. 11 (top panel). A seasonal pattern can be distinguished from this figure. From January on, there is an upward trend until the start of summer, which suggests an increasing variation in temperature for ERA15/REMO when approaching summer. During summer this ratio again approaches one, suggesting a similar standard deviation for the observed and ERA15/REMO temperature. Around midsummer this ratio is increasing again, resulting in a larger spread in temperature for ERA15/REMO during this period. The area-weighted average ratio of 1.05 suggests that the average spread in temperature for ERA15/REMO is larger than that for the observations. The bottom panel of Fig. 11 represents the spread in average temperature differences between the ERA15/REMO $\left(\bar{T}_{\text {era }}\right)$ and observed temperature $\left(\bar{T}_{\text {obs }}\right)$. Especially during summer the difference between $\bar{T}_{\text {era }}$ and $\bar{T}_{\text {obs }}$ tends to be larger, suggesting a much warmer 17-year average for ERA15/REMO than for the observations. The 17-year average temperature appears to be warmer for ERA15/REMO throughout the entire year for almost all subbasins. The overal area-weighted average temperature difference of $0.86^{\circ} \mathrm{C}$ suggests that the average temperature for ERA15/REMO is larger than that for the observations.
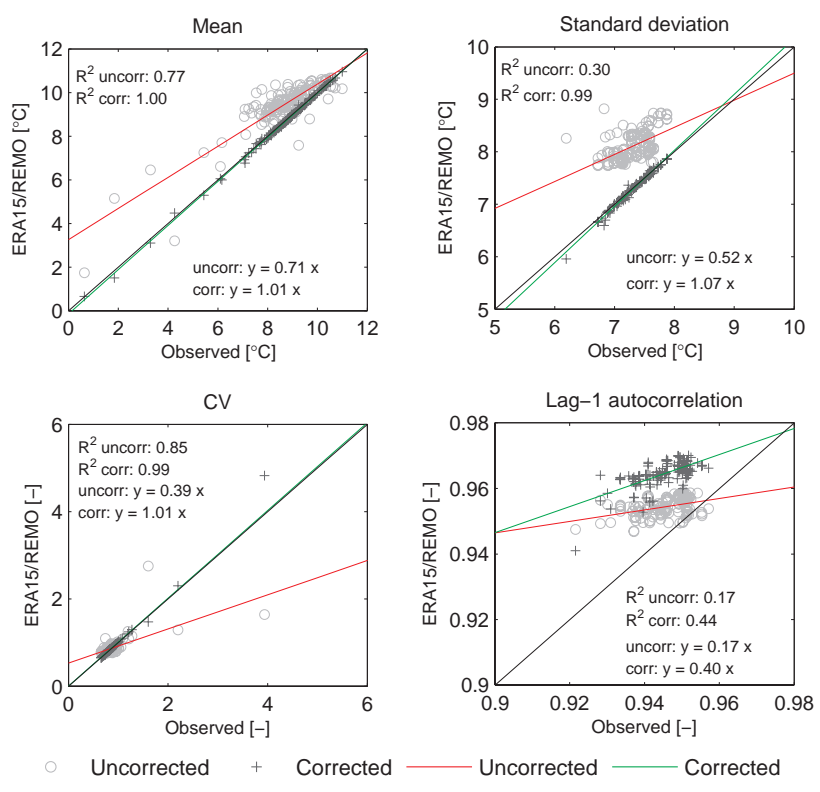

Fig. 12. Scatter plots of the statistics of the observed temperature versus the corrected and uncorrected ERA15/REMO temperature. The statistics are calculated for each sub-basin over the period 1979-1995. In each subplot the square of the correlation coefficient $\left(R^{2}\right)$ and slope of the linear regression line are plotted. The black line represents the $x=y$ line.

\subsubsection{Statistics}

The most important statistics for the uncorrected and corrected ERA15/REMO temperature are plotted against those of the observations in Fig. 12. The considered statistics are the mean, standard deviation, CV and lag-1 autocorrelation. They are calculated over the entire period 1979-1995, for each sub-basin separately. As mentioned before, the chosen method of bias correction only corrects for the mean and the standard deviation. This is clearly visible in the plots of the mean, standard deviation and CV, where the corrected ERA15/REMO statistics are almost equal to those of the observations. Despite the fact that the correlation coefficients between the lag-1 autocorrelations for ERA15/REMO and the observations have increased for the corrected situation, the points have moved further away from the $x=y$ line. However, considering the scale of the y-axis, this result seems to be of minor importance.

\subsection{Relation between precipitation and temperature}

The employed bias correction method adjusts precipitation and temperature separately. It is possible that there exists a certain relation between these variables, which is disturbed after applying a bias correction. Dependencies between the daily precipitation and temperature are shown in a scatter density plot (Fig. 13), taking into account values from all 

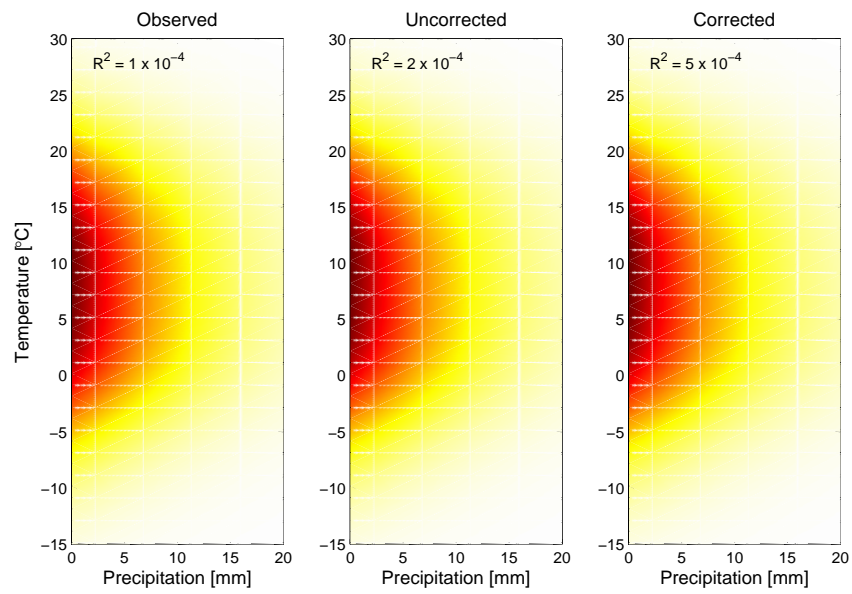

Fig. 13. Dependency between the daily precipitation and temperature of the observed and uncorrected and corrected ERA15/REMO data for the period 1979-1995. The squared correlation coefficient for the correlation between precipitation and temperature is shown as well.

sub-basins. Results are shown for the observations and the uncorrected and corrected ERA15/REMO data. The extremely low $R^{2}$ for the correlation between precipitation and temperature indicates the absence of correlation. From this figure we can conclude that the pattern of points and correlation coefficient are not drastically disturbed after the bias correction is applied. This result is robust on a seasonal level as well.

\subsection{Validation}

\subsubsection{Introduction}

The previous analysis focused on the bias correction for the entire period 1979-1995. In climate impact studies, the bias correction parameters are often determined for a certain reference period, and subsequently applied to a future climate period. Therefore we have selected 10 years from the period 1979-1995 as a calibration period for determining the correction parameters, and applied the determined correction parameters for the remaining 7 years, known as the validation period. With this we want to evaluate how well the method of Leander and Buishand (2007) is capable of correcting another period for which the parameters were not determined. This analysis is split into two parts, wherein the first part uses the period 1979-1988 as the calibration period and the period 1989-1995 as the validation period. The second analysis takes 100 samples, in which each sample consists of 10 randomly chosen years from the period 1979-1995 which are used for calibration and the remaining 7 years are used for validation. With this analysis we want to quantify the uncertainty associated with the selection of 10 calibration and 7 validation years.
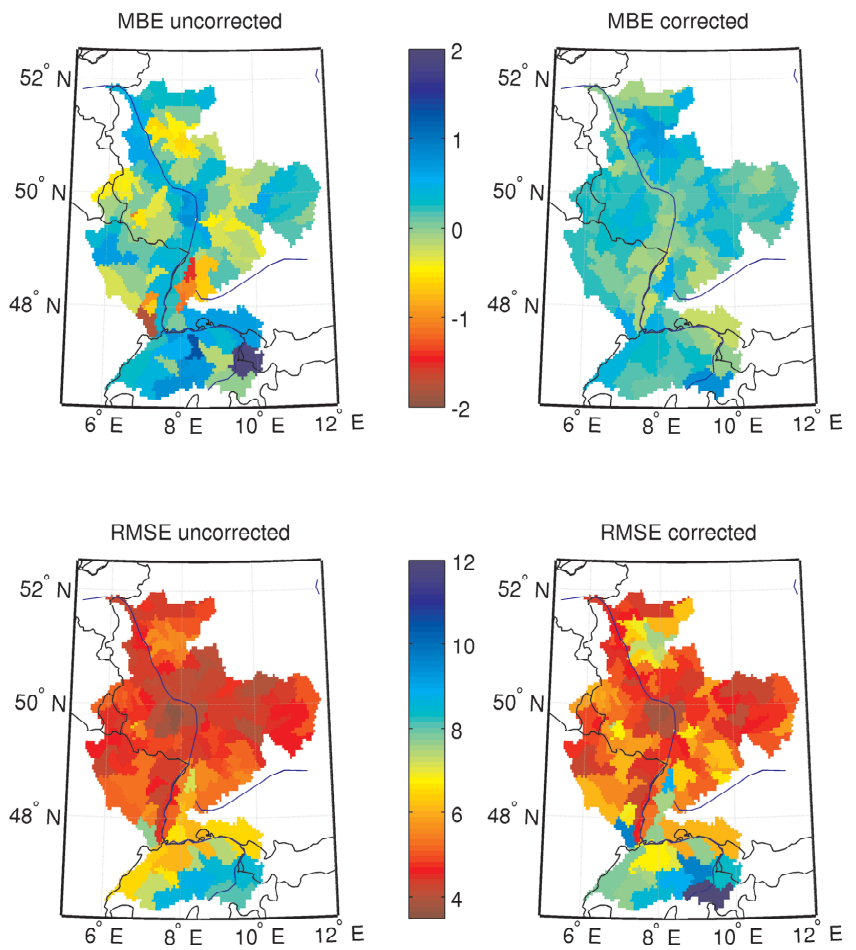

Fig. 14. Top: MBE for the uncorrected and corrected ERA15/REMO precipitation [mm] per sub-basin for the validation period 1989-1995. Bottom: RMSE for the uncorrected and corrected ERA15/REMO precipitation [mm] per sub-basin for the validation period 1989-1995.

\subsubsection{Continuous period}

The previously described bias correction method has been applied to determine the correction parameters for the period 1979-1988. These parameters have been used to correct precipitation and temperature for the period 1989-1995. Similar to Fig. 4, the MBE for the uncorrected and corrected ERA15/REMO precipitation per sub-basin are shown in the top panel of Fig. 14 for the validation period 1989-1995. Spatial precipitation differences have been minimized for the corrected situation, although less notable than for the analysis for the entire period 1979-1995. We already noticed that the RMSE between the observed and ERA15/REMO precipitation was not improved for the corrected situation when considering the entire period 1979-1995. Looking at the validation period (bottom panel Fig. 14), it seems that the RMSE even increases for the corrected situation. This may result in worse performance of a hydrological model, if the parameters were used to correct a meteorological forcing dataset for a period for which the parameters were not determined.

Average monthly precipitation sums plus or minus one standard deviation are shown in the top panel of Fig. 15 for the validation period 1989-1995. The correction method does not lead to an improvement for the months February, 

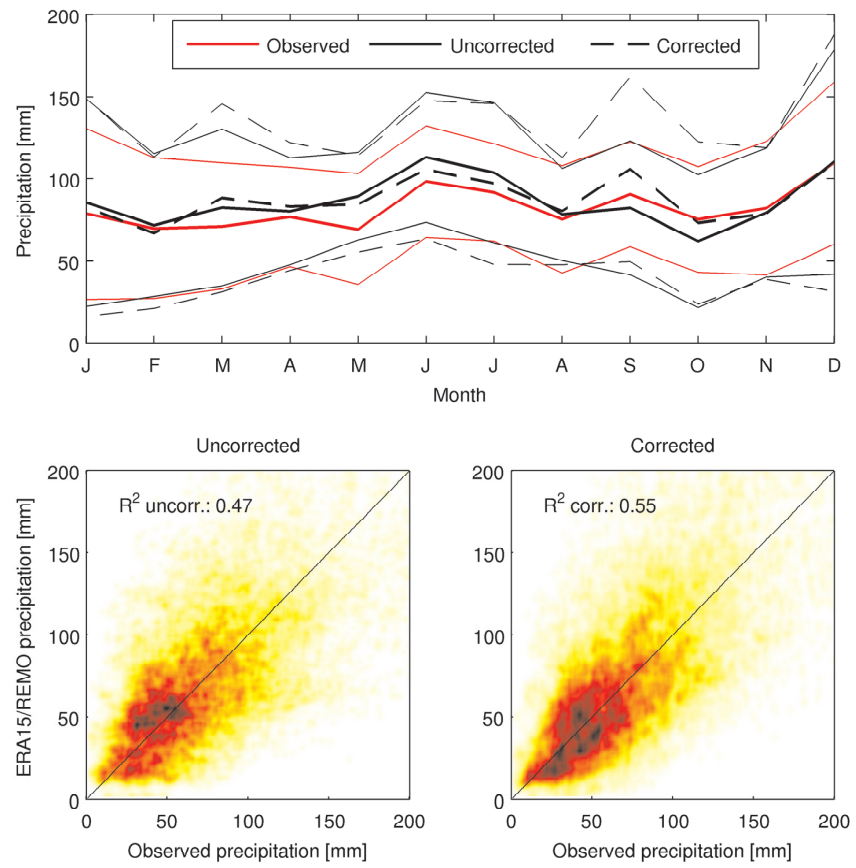

Fig. 15. Top: average monthly precipitation sums $[\mathrm{mm}]$ for the observations and the uncorrected and corrected ERA15/REMO data for the validation periond 1989-1995 (solid lines). Average monthly precipitation sums +/- one standard deviation are shown as well (thin lines). Bottom: scatter densities for the uncorrected and corrected ERA15/REMO and observed yearly monthly precipitation sums per sub-basin for the validation periond 1989-1995. $R^{2}$ coefficients for the uncorrected and corrected situation are shown as well.

March, April, August and September. Considering the standard deviations, it seems that especially for March and September there are some years for which the correction is too wet. Similar to Fig. 5, the monthly precipitation sums for each separate year and individual sub-basin are plotted in the scatter density plots of Fig. 15 (bottom panel) for the uncorrected and corrected situation for the validation period. Considering the $R^{2}$ coefficients, we can see an overal improvement, although less important than for the entire calibration period 1979-1995. Based on these results we conclude that the determined correction parameters are able to correct ERA15/REMO precipitation in a validation period during the warmer summer months, but that the uncorrected precipitation is closer to the observations for most winter months and especially for March and September.

The MBE for the uncorrected and corrected ERA15/REMO temperature per sub-basin are shown in the top panel of Fig. 16 for the validation period. It appears that the determined parameters for the calibration period 1979-1988 work very well for the validation period, too. Also the RMSE between the daily ERA15/REMO temperature and observed temperature is minimized, meaning that the daily temperature values are corrected for the validation period as well (bottom panel Fig. 16).
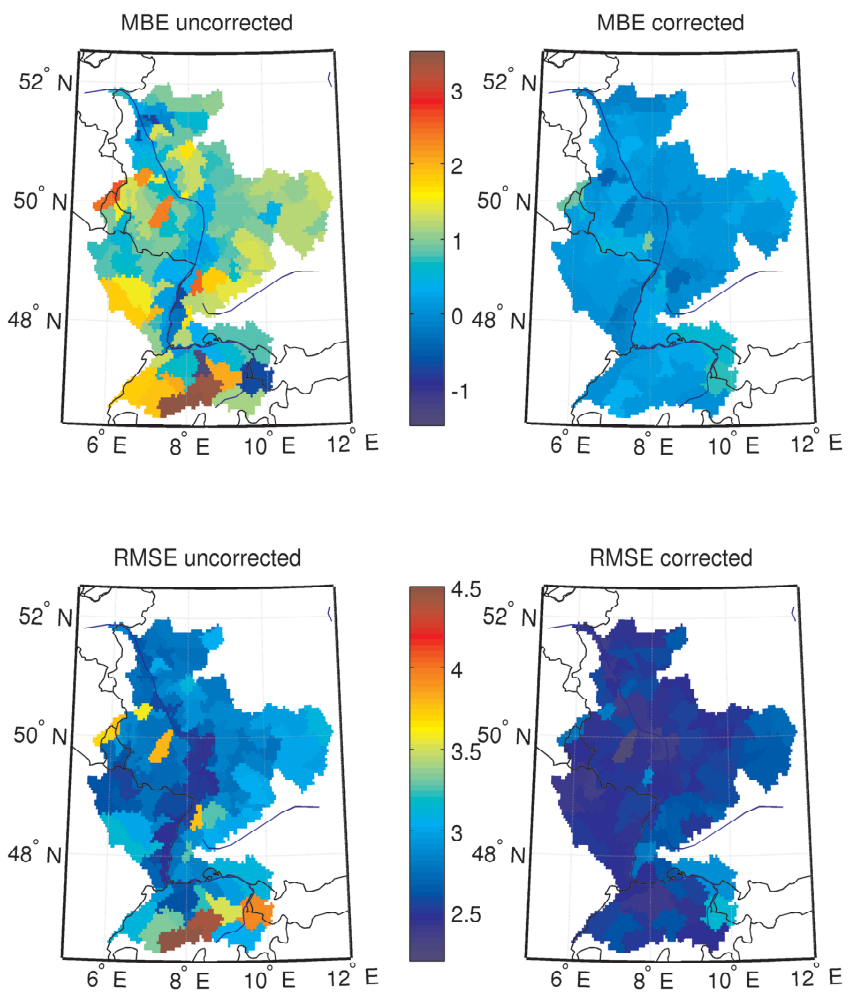

Fig. 16. Top: MBE for the uncorrected and corrected ERA15/REMO temperature $\left[{ }^{\circ} \mathrm{C}\right]$ per sub-basin for the validation period 1989-1995. Bottom: RMSE for the uncorrected and corrected ERA15/REMO temperature $\left[{ }^{\circ} \mathrm{C}\right]$ per sub-basin for the validation period 1989-1995.

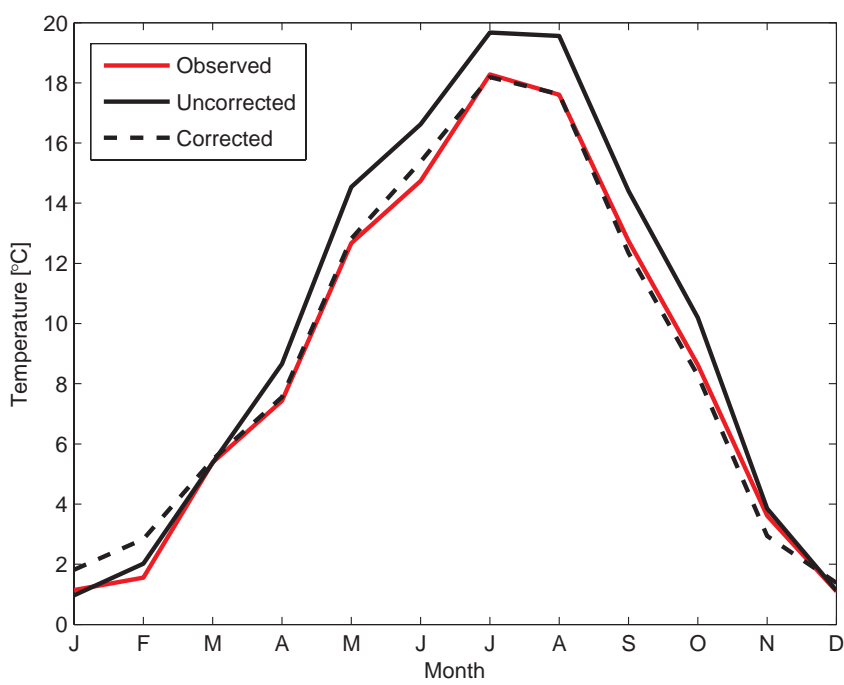

Fig. 17. Area-weighted monthly temperature $\left[{ }^{\circ} \mathrm{C}\right]$ over the entire Rhine basin for the validation period 1989-1995. Results are shown for the observations and the uncorrected and corrected ERA15/REMO. 

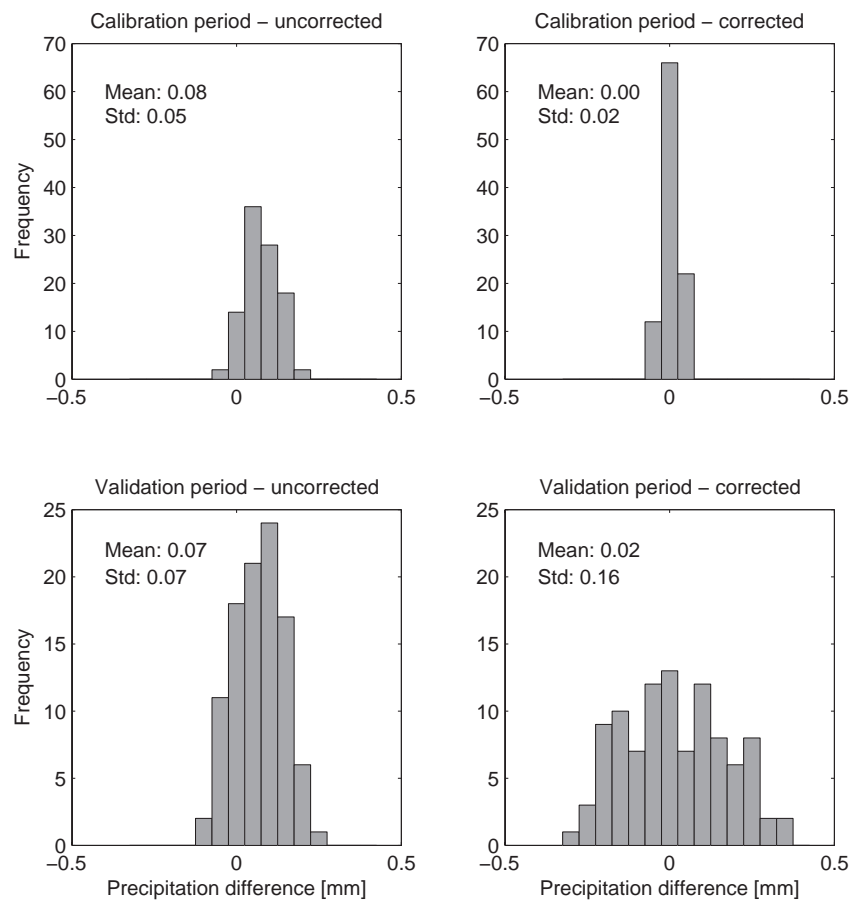

Fig. 18. Top: histograms of 100 samples of average daily precipitation differences between the uncorrected and observed (left), and between the corrected and observed precipitation (right) for the calibration period. Bottom: similar, but for the validation period.

Monthly temperature averages for the validation period are shown in Fig. 17. The correction parameters for temperature adjust the average monthly temperatures very well for the validation period, except for the months November, December, January and February.

\subsection{Random sampling}

For this analysis we took 100 random samples of 10 years from the 17 years available, and used these years to determine the correction parameters. The determined parameters have been used to correct the ERA15/REMO data for the remaining 7 years, denoted as the validation period. For each validation sample we calculated the average daily precipitation and temperature value, averaged over the entire Rhine basin. The differences between the uncorrected and observed, and the corrected and observed values are taken as a measure of how well the method performs for a randomly chosen period for calibration and validation. The results of this analysis are shown in the histograms of Fig. 18 and Fig. 19 for precipitation and temperature, respectively. It is clear that for the majority of samples for the calibration period the precipitation difference is smaller for the corrected situation. For the validation period it turns out that for the corrected situation the spread in precipitation differences increases, but that the overal average has improved. The total absolute differences for the 100 samples are 7.99, 2.01, 8.13
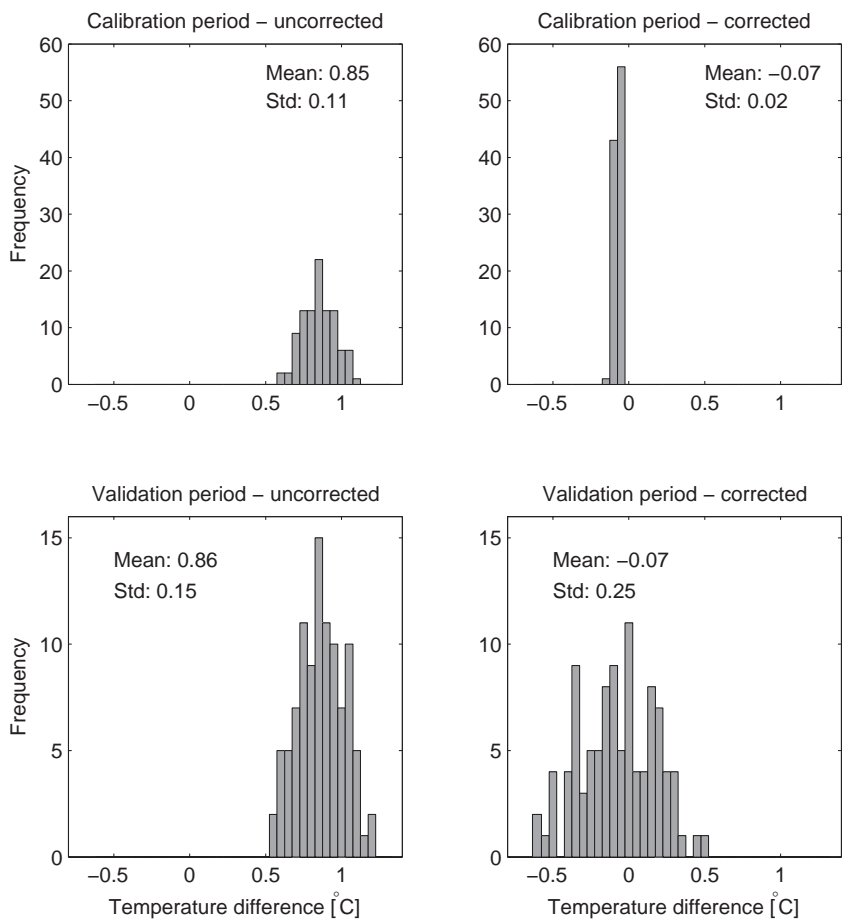

Fig. 19. Top: histograms of 100 samples of average daily temperature differences between the uncorrected and observed (left), and between the corrected and observed temperature (right) for the calibration period. Bottom: similar, but for the validation period.

and $13.04 \mathrm{~mm}$ for the uncorrected and corrected precipitation during the calibration period, and uncorrected and corrected precipitation during the validation period, respectively. It is not clear what causes this large spread in precipitation difference for the validated corrected precipitation. A possible explanation could be some low frequency components in the rainfall series. This is not further investigated as such in this paper. We expect that larger sample sizes (in excess of 10 years) lead to a decrease in the spread of precipitation biases. Therefore, it is recommended to use as many years as possible to have the largest sample size for determining the correction parameters. Results for temperature look more promising. Large frequencies are now found to be centered around zero temperature difference for the validated corrected temperature.

\section{Conclusions and perspectives}

\subsection{Conclusions}

This study presents an application of a bias correction method to downscaled ERA15 precipitation and temperature, and investigates how capable this method is for correcting these data for a bias with respect to observations. We also analyzed how well the precipitation and temperature data are corrected during a certain validation period, using parameters 
determined for a calibration period. The most important results are:

1. Precipitation and temperature for the uncorrected ERA15/REMO were found to be too wet and too warm for most of the Rhine basin;

2. Precipitation and temperature are corrected very well for the calibration period 1979-1995;

3. The RMSE of the daily precipitation difference between the ERA15/REMO and observed precipitation is not smaller for the corrected precipitation values;

4. The correction method also seems to improve the fraction of wet days for precipitation and lag-1 autocorrelations for precipitation and temperature;

5. Bootstrapping for the parameters $a$ and $b$ showed that the uncertainty is largest in correcting for the mean and the spread for these parameters is largest during winter;

6. Determined correction parameters for the period 19791988 are able to correct precipitation and temperature for the period 1989-1995. Precipitation correction during the validation period works well, especially for May, June, July and October. However, the validation results in over-adjustment of the monthly precipitation in March and September;

7. The RMSE has increased for the corrected ERA15/REMO precipitation during the validation period. This is mainly due to the over-adjustment of precipitation in March and September;

8. When taking random years for calibration, the spread in MBE between ERA15/REMO and the observations has increased for the corrected situation during the validation period. However, the overal average MBE has decreased for the corrected precipitation during the validation period;

9. Temperature is corrected in a satisfactory manner for the randomly selected years used as validation period;

\subsection{Perspectives}

In Hurkmans et al. (2010) we use the bias-corrected precipitation and temperature to calibrate VIC and do a climate impact study. VIC, however, needs other meteorological forcing data as well, such as wind speed, incoming short- and longwave radiation, vapour pressure and specific humidity. Correcting precipitation and temperature only would violate the energy balance present in ERA15/REMO. Unfortunately there were no observations for the other forcing variables available at the temporal and spatial resolution used in this study and they are therefore left uncorrected. For future work this could be addressed using a multi-variate bias correction method, in which the forcing variables are corrected preserving the energy balance. Such methods are currently unknown to us and probably very time consuming. However, for calibration purposes we expect precipitation and temperature to have the largest influence on the performance of the hydrological model. Moreover, for operational purposes water managers would be more interested in probabilities than uncertainties. For a water manager the probability for e.g. a discharge exceeding a certain threshold would have more importance than the uncertainty present in RCM data and subsequently the hydrological model output. Therefore, it is very useful for ongoing research on climate impact studies to address the uncertainty in the RCM and hydrological model, and translate this to the probability of e.g. the occurrence of floods and droughts. We already mentioned that this method of bias correction can easily be applied to other river basins if enough meteorological data are available. However, the results in the current study are mainly focusing on the Rhine basin. Therefore, it is uncertain how the correction methodology performs in other river basins (with other data sets) and therefore it is not possible to define operational applications. Thus, it is recommended to apply the correction method to several river basins and RCMs with several resolutions in order to obtain information which could be useful for operational applications.

Currently there are other existing methods for bias correction available. For example Hay et al. (2002) applied a gamma transform to correct RegCM2 precipitation data. They found that the corrected precipitation data did not contain the day-to-day variability present in the observed data set. We have found that the correction method applied in the current study does not lead to a decrease in RMSE between simulated and observed precipitation amounts. This suggests that our method is not capable of preserving the day-to-day variability present in the observed data set either. The gamma transform is also evaluated by Piani et al. (2010). They show that the gamma transform is capable of correcting for seasonal means, but they do not show how the correction performs on a daily basis. We think the day-to-day variability is an important aspect when it comes to hydrological modeling, because for hydrological applications it is important that the model is capable of simulating the correct amount of streamflow at the right time and is therefore dependent on the correct timing of precipitation events. A further interesting experiment would be to evaluate the improvement of the hydrological model simulation with and without the biascorrected precipitation fields, using bias-corrected precipitation fields from various correction methods (van Pelt et al., 2009; Hay et al., 2002; Déqué, 2007; Piani et al., 2010). This was also suggested by Piani et al. (2010).

We noticed an increase in the RMSE for daily precipitation differences between ERA15/REMO and the observations for the validation period. Therefore it is recommended to determine the correction parameters for the same period as for which the hydrological model will be calibrated. The 
uncertainty with the selection of 10 years for calibration and 7 years for validation was quantified by taking 100 samples, in which each sample consists of 10 randomly selected years which are used for calibration and the remaining 7 years are used for validation. This resulted in the fact that the spread in MBE between ERA15/REMO and the observations increased for the corrected situation during the validation period. At this moment, it is not clear what causes this difference for the validated corrected precipitation. A possible explanation could be some low frequency components in the rainfall series. More research considering low frequency components is recommended. However, the overal average MBE has decreased for the corrected ERA15/REMO precipitation during the validation period.

In Hurkmans et al. (2010), we apply the same bias correction method to correct for the bias between a climate run of the 20st century and the observations. This results in a set of correction parameters which are different from those derived in the current study. The climate run of the 20st century is actually an ECHAM5 run which is downscaled with REMO (Jacob, 2001). The correction parameters are subsequently applied to the future climate scenarios. These future scenarios were created by forcing the ECHAM5 model with IPCC carbon emission scenarios (A1B, A2 and B1; IPCC, 2000) and finally downscaling with REMO (Jacob, 2001). We have shown that the derived correction parameters in a calibration period are able to correct precipitation and temperature in a validation period. This strategy of climate impact assessment has been applied before by others; for example van Pelt et al. (2009) applied a bias correction to downscaled ECHAM5 data, were ECHAM5 was downscaled with RACMO2. They assessed the impact of climate change on discharge for the Meuse basin by forcing ECHAM5 with a transient (1950-2100) simulation of ECHAM5 using observed greenhouse gases for 1950-2000, and using the SRES A1B scenario for the 21st century. Lenderink et al. (2007) used the hydrological model Rhineflow driven by meteorological data from a 90-year simulation with the HadRM3H RCM for both present-day and future climate, using the same bias correction for future climate as detected for present-day climate. In all these studies, it is assumed that the bias correction parameters in the present-day climate remain invariate in future climate projections. However, Christensen et al. (2008) demonstrated that it is indeed necessary to correct for a bias present in the RCM, but that the common assumption of bias cancellation (invariance) in climate change projections can have serious limitations when temperatures in the warmest months exceed $4-6^{\circ} \mathrm{C}$ above present day conditions. Thus correction parameters derived for the current climate cannot always be used to correct precipitation and temperature in a future climate. This study also demonstrates that the assumption of a constant model bias may not hold, because the determined correction parameters may result in over-adjustment of precipitation during the validation period. For hydrological applications this may lead to overestimation of the observed discharges. Therefore, if possible, we should always validate the simulated discharges with observed discharges when it comes to hydrological modeling with biascorrected RCM data. This would only be possible with RCM data of the current climate, because observed discharges are obviously not available for a future climate.

Acknowledgements. This research was financially supported by the European Commission through the FP6 Integrated Project NEWATER and the BSIK ACER project of the Dutch Climate Changes Spatial Planning programme. The authors would like to thank Adri Buishand (KNMI) for fruitful discussions concerning bias corrections. Daniela Jacob from the Max Planck Institut für Meteorologie in Hamburg, Germany, is kindly acknowledged for providing the downscaled reanalysis data. The international Commission for the Hydrology of the Rhine basin (CHR) is acknowledged for providing the observed precipitation and temperature data.

Edited by: F. Pappenberger

\section{References}

Aldrich, J.: R. A. Fisher and the Making of Maximum Likelihood 1912-1922, Stat. Sci., 12, 162-176, 1997.

Bergström, S. and Forsman, A.: Development of a conceptual deterministic rainfall-runoff model, Nordic Hydrology, 4, 147-170, 1973.

Beven, K.: Changing ideas in hydrology - the case of physically based models, J. Hydrol., 105, 157-172, 1989.

Brandsma, T. and Buishand, T.: Rainfall generator for the Rhine basin: Multi-site generation of weather variables by nearestneighbour resampling, KNMI Publication, 186-II, 58 pp., 1999.

Christensen, J., Boberg, F., Christensen, O., and Lucas-Picher, P.: On the need for bias correction of regional climate change projections of temperature and precipitation, Geophys. Res. Lett., 35, L20709, doi:10.1029/2008GL035694, 2008.

Dällenbach, F.: Gebietsniederschlag Schweiz: Interpolation und Berechnung der Niederschlagsdaten. Gutachten im Auftrag der Landeshydrologie und Geologie (LHG), Tech. rep., Meteotest, Bern, Switzerland., 2000.

de Wit, M. and Buishand, T.: Generator of rainfall and discharge extremes (GRADE) for the Rhine and Meuse basins, KNMI Publication, 218, 2007.

de Wit, M., van den Hurk, B., Warmerdam, P., Torfs, P., Roulin, E., and van Deursen, W.: Impact of climate change on lowflows in the river Meuse, Clim. Change, 82, 351-372, doi: 10.1007/s10584-006-9195-2, 2007.

Déqué, M.: Frequency of precipitation and temperature extremes over France in an anthropogenic scenario: Model results and statistical correction according to observed values, Global and Planetary Change, 57, 16-26, doi:10.1016/j.gloplacha.2006.11.030, 2007.

Eberle, M., Buitenveld, H., Beersma, J., Krahe, P., and Wilke, K.: Estimation of extreme floods in the river Rhine basin by combining precipitation-runoff modelling and a rainfall generator, in: Proceedings International Conference on Flood Estimation, Berne, 2002, 459-468, CHR report II-17. International Comis- 
sion for the Hydrology of the Rhine basin (CHR), Lelystad, The Netherlands, 2002.

Eberle, M., Buitenveld, H., Krahe, P., and Wilke, K.: Hydrological modelling in the river Rhine basin, Part III: Daily HBV model for the Rhine basin, Report No. 1451., Tech. rep., Bundesanhalt für Gewässerkunde (BfG), Koblenz, Germany, 2005.

Efron, B. and Tibshirani, I.: An Introduction to the Bootstrap, Chapman and Hall/CRC, 1994.

Frei, C., Christensen, J., Déqué, M., Jacob, D., Jones, R., and Vidale, P.: Daily precipitation statistics in regional climate models: Evaluation and intercomparison for the European Alps, J. Geophys. Res., 108(D3), 4124, doi:10.1029/2002JD002287, 2003.

Furrer, E. and Katz, R.: Improving the simulation of extreme precipitation events by stochastic weather generators, Water Resour. Res., 44, W12439, doi:10.1029/2008WR007316, 2008.

Hagemann, S. and Jacob, D.: Gradient in the climate change signal of European discharge predicted by a multi-model ensemble, Clim. Change, 81, 309-327, doi:10.1007/s10584-006-9225-0, 2007.

Hagemann, S., Arpe, K., Bengtsson, L., and Kirchner, I.: Validation of precipitation from ERA40 and an ECHAM4.5 simulation nudged with ERA40 data, in: ERA-40 Project Report Series: 3. Workshop on Reanalysis, 5-9 November 2001, ECMWF, Reading, England, pp. 211-228., 2002.

Hay, L., Clark, M., Wilby, R., Gutowski, W., Leavesley, G., Pan, Z., Arritt, R., and Takle, E.: Use of regional climate model output for hydrologic simulations, J. Hydrometeorol., 3, 571-590, 2002.

Hurkmans, R., de Moel, H., Aerts, J., and Troch, P.: Water balance versus land surface model in the simulation of Rhine river discharges, Water Resour. Res., 44, W01418, doi:10.1029/ 2007WR006168, 2008.

Hurkmans, R., Terink, W., Uijlenhoet, R., Torfs, P., Jacob, D., and Troch, P.: Changes in streamflow dynamics in the Rhine basin under three high-resolution regional climate scenarios, J. Climate, 23, 679-699, doi:10-1175/2009JCLI3066.1, 2010.

IPCC: Special Report Emission Scenarios - Summary for Policy makers - A Special Report of IPCC Working Group III, Tech. rep., 2000.

Jacob, D.: A note to the simulation of the annual and inter-annual variability of the water budget over the Baltic Sea drainage basin, Meteorol. Atmos. Phys., 77, 61-73, 2001.

Jacob, D., Göttel, H., Kotlarski, S., Lorenz, P., and Sieck, K.: Klimaauswirkungen und Anpassung in Deutschland - Phase 1: Erstellung regionaler Klimaszenarien für Deutschland, Umweltbundesamt, 2008.

Kallberg, P.: An overview of the ERA-40 analyses, in: ERA-40 Project Report Series 3. Workshop on Reanalysis, 5-9 November 2001, ECMWF, Reading, England, pp. 31-40, 2002.

Kay, A., Jones, R., and Reynard, N.: RCM rainfall for UK flood frequency estimation. II. Climate change results, J. Hydrol., 318, 163-172, doi:10.1016/j.jhydrol.2005.06.013, 2006.

Kleinn, J., Frei, C., Gurtz, J., Lüthi, D., Vidale, P., and Schär, C.: Hydrologic simulations in the Rhine basin driven by a regional climate model, J. Geophys. Res., 110, D04102, doi: 10.1029/2004JD005143, 2005.
Kotlarski, S., Block, A., Böhm, U., Jacob, D., Keuler, K., Knoche, R., Rechid, D., and Walter, A.: Regional climate model simulations as input for hydrological applications: evaluation of uncertainties, Adv. Geosci., 5, 119-125, 2005, http://www.adv-geosci.net/5/119/2005/.

Leander, R. and Buishand, T.: Resampling of regional climate model output for the simulation of extreme river flows, J. Hydrol., 332, 487-496, doi:10.1016/j.jhydrol.2006.08.006, 2007.

Lenderink, G., Buishand, A., and van Deursen, W.: Estimates of future discharges of the river Rhine using two scenario methodologies: direct versus delta approach, Hydrol. Earth Syst. Sci., 11, 1145-1159, 2007, http://www.hydrol-earth-syst-sci.net/11/1145/2007/.

Liang, X., Lettenmaier, D., Wood, E., and Burges, S.: A simple hydrologically based model of land surface water and energy fluxes for general circulation models, J. Geophys. Res., 99, 1441514428, 1994.

Lindström, G., Johansson, B., Persson, M., Gardelin, M., and Bergström, S.: Development and test of the distributed HBV-96 hydrological model, J. Hydrol., 201, 272-288, 1997.

Middelkoop, H., Daamen, K., Gellens, D., Grabs, W., Kwadijk, J., Lang, H., Parmet, B., Schädler, B., Schulla, J., and Wilke, K.: Impact of climate change on hydrological regimes and water resources management in the Rhine basin, Clim. Change, 49, 105128, 2001.

Mülders, R., Parmet, B., and Wilke, K.: Hydrological modelling in the river Rhine basin, final report. Report No. 1215., Tech. rep., Bundesanhalt für Gewässerkunde (BfG), Koblenz, Germany, 1999.

Piani, C., Haerter, J., and Coppola, E.: Statistical bias correction for daily precipitation in regional climate models over Europe, Theoretical and Applied Climatology, 99, 187-192, doi:10.1007/ s00704-009-0134-9, 2010.

Shabalova, M., van Deursen, W., and Buishand, T.: Assessing future discharge of the river Rhine using regional climate model integrations and a hydrological model, Clim. Res., 23, 233-246, 2003.

Sprokkereef, E.: Eine hydrologische Datenbank für das Rheingebiet, Tech. rep., RIZA, 2001.

Steele-Dunne, S., Lynch, P., McGrath, R., Semmler, T., Wang, S., Hanafin, J., and Nolan, P.: The impacts of climate change on hydrology in Ireland, J. Hydrol., 356, 28-45, doi:10.1016/j.jhydrol. 2008.03.025, 2008.

van Pelt, S. C., Kabat, P., ter Maat, H. W., van den Hurk, B. J. J. M., and Weerts, A. H.: Discharge simulations performed with a hydrological model using bias corrected regional climate model input, Hydrol. Earth Syst. Sci., 13, 2387-2397, 2009, http://www.hydrol-earth-syst-sci.net/13/2387/2009/.

Weerts, A., Meißner, D., and Rademacher, S.: Input Data RainfallRunoff Model Operational Systems FEWS-NL \& FEWS-DE, Tech. rep., Deltares, 2008.

White, W.: Spatio-temporal structure of precipitation in the Moselle basin with particular regard to flood events, Tech. rep., University of Trier, Germany, 2001.

Zolina, O., Kapala, A., Simmer, C., and Gulev, S.: Analysis of extreme precipitation over Europe from different reanalyses: a comparative assessment, Global Planet. Change, 44, 129-161, doi:10.1016/j.gloplacha.2004.06.009, 2004. 